\title{
Mapping past, present and future dew and rain water resources for biocrust evolution in southern Africa
}

\author{
Marc Muselli1,2, Daniel Beysens ${ }^{2,3^{*}}$ \\ ${ }^{1}$ Università di Corsica Pasquale Paoli, Avenue du 9 septembre, BP 52, 20250 Corte, France. \\ ${ }^{2}$ OPUR, 2 rue Verderet, 75016 Paris, France. \\ ${ }^{3}$ Physique et Mécanique des Milieux Hétérogènes, CNRS, ESPCI Paris - PSL University, Sorbonne Université, Sorbonne Paris Cité, 10 \\ rue Vauquelin, 75005 Paris, France. \\ * Corresponding author. Tel.: +33(0)689864717. E-mail: daniel.beysens@espci.fr
}

\begin{abstract}
Biocrust sustainability relies on dew and rain availability. A study of dew and rain resources in amplitude and frequency and their evolution is presented from year 2001 to 2020 in southern Africa (Namibia, Botswana, South Africa) where many biocrust sites have been identified. The evaluation of dew is made from a classical energy balance model using meteorological data collected in 18 stations, where are also collected rain data. One observes a strong correlation between the frequency of dew and rain and the corresponding amplitudes. There is a general tendency to see a decrease in dew yield and dew frequency with increasing distance from the oceans, located west, east and south, due to decreasing $\mathrm{RH}$, with a relative minimum in the desert of Kalahari (Namibia). Rain amplitude and frequency decreases when going to west and north. Short-term dew/rain correlation shows that largest dew yields clearly occur during about three days after rainfall, particularly in the sites where humidity is less.

The evolution in the period corresponds to a decrease of rain precipitations and frequency, chiefly after 2010, an effect which has been cyclic since now. The effect is more noticeable towards north. An increase of dew yield and frequency is observed, mainly in north and south-east. It results in an increase of the dew contribution with respect to rain, especially after 2010. As no drastic changes in the distribution of biomass of biocrusts have been reported in this period, it is likely that dew should compensate for the decrease in rain precipitation. Since the growth of biocrust is related to dew and rain amplitude and frequency, future evolution should be characterized by either the rain cycle or, due to global change, an acceleration of the present tendency, with more dew and less rainfalls.
\end{abstract}

Keywords: Biocrust; Dew and rain evolution; Dew/rain ratio; Dew/rain correlation; Southern Africa; Climate change.

\section{INTRODUCTION}

Biocrust are typically found in drylands with arid or semiarid ecosystems. In great interaction with the soil, biocrust concern cyanobacteria, lichens, algae and mosses. These organisms contribute strongly in the ecosystem's functioning and plant organization and are present all around the world.

Numerous works detail their physical, chemical and biological characteristics in semi-arid or arid climates. Negev (Jacobs et al., 2002; Kidron and Tal, 2012), Europe (Raggio et al., 2021), Spain (Cano-Díaz et al., 2018), China (Yao et al., 2019), USA (Aguirre-Gutiérrez et al., 2019) are a few examples. According to Chen et al. (2020), biocrust correspond to $30 \%$ of global drylands. It is in China, Australia, North America and Spain in Europe that are found the more studied biocrust sites. In the present study, a representative area for biocrust studies was chosen in a less investigated area, the southern part of Africa. Namibia, South Africa and Bostwana are the main countries involved in this study, representing 18 sites of measurement ( 7 in Namibia, 7 in South Africa and 4 in Bostwana, respectively). One should note that these locations are based on previous works of a few scholars within certain research sites and cannot obviously replace an objective map. A map of soil can help to locate biocrust, it is given in Fig. 1 together with the above studied sites.

Moisture from atmosphere (rainfall, fog, dew, vapor absorption) plays an important role in sustaining life in arid or semi-arid climates. Pan et al. (2010) concluded on the mutual enhanced effect between dew and artificially revegetation ecosystems in the arid desert ecosystem in Shapotou (China). Li et al. $(2021 \mathrm{a}, \mathrm{b})$, in recent papers, determine that biocrust benefits from non-rainfall water deposition and modify their distribution in drylands soils. Dewfall can be presented as a critical source of water in deserts environments allowing to determine the sustainability of sand to stabilize planted vegetation (Zhuang and Zhao, 2017). Dew, fog and rain can play an important role for the development of biocrust in semiarid regions. Kidron (2019) suspects dew to be a necessary water source for cyanobacteria. Biocrust alter non-rainfall distribution by depth, concentrating it in the surface (Li et al., $2021 \mathrm{a}, \mathrm{b})$. Biocrust can boost the use of non-rainfall water according to Ouyang et al. (2017). Büdel et al. (2009) conclude their study by noting that the time frequency of rain precipitations is more important than their amount.

The amount and frequency of rain and dew are then the main factors which influence the growth of biocrust. This paper aims to evaluate the evolution of these contributions to over a long period of time (20 years, from 2001 to 2020) in order to put in evidence the long term trend and extrapolate to the near future. Because certain data are lacking before 2011, a few analyses are restricted to 10 years (2011-2020).

The paper is organized as follows. After having reported on measurements and methods in Section 2, mainly concerning the physical model used to determine the dew yields, Section 3 is devoted to the main results with maps i) for dew and rain atmospheric deposition, ii) cumulative rainfall and dew yields 
comparisons and iii) short time and longtime evolution of dew and rainfalls yield and frequency. A Section 4 is devoted to discussions and relation of the rain and dew studies with biocrust.

\section{METEOROLOGICAL DATA AND METHODS 2.1 Dew yield estimation from meteorological data}

In order to estimate the dew potential, Beysens (2016) developed an energy balance model which, thanks to some approximation, uses only a few classical meteorological data without adjustable parameters: cloud cover ( $N$, oktas), wind speed $\left(V, \mathrm{~m} \mathrm{~s}^{-1}\right)$, air temperature $\left(T_{a},{ }^{\circ} \mathrm{C}\right)$, air relative humidity (RH, \%) and dew point temperature $\left(T_{d},{ }^{\circ} \mathrm{C}\right)$. Near the ground level where dew forms, in the atmospheric boundary layer, the contribution from water vapor (about $0.2-2 \%$ by volume) and, to a lower extent, carbon dioxide (about $0.03 \%$ in volume) is of great importance for the radiative balance, with radiation from water vapor being by far the more important of the two. The results are concerned with dew yields $h\left[\mathrm{~mm}(\Delta t)^{-1}\right]$ where $\Delta t$ corresponds to the period (in hours) of the analyzed data. It is assumed that the substrate emissivity is unity (which is close to the emissivity $\approx 0.98$ of a wet substrate, see Trosseille et al., 2021) and is thermally insulated from below. The data can be obtained from the airport meteo stations by using the following formulation:

$h=\left(\frac{\Delta t}{12}\right)(H L+R E)$

The factor $\Delta t$ is the measurement period of the data (here 6, 3 or $1 \mathrm{~h}$. depending on the stations). The data for $h>0$ correspond to condensation and $h<0$ to evaporation, which have to be discarded. The quantity $H L$ represents the convective heat losses between air and condenser, with a cut-off for windspeed $V>V_{0}=4.4 \mathrm{~m} \mathrm{~s}^{-1}$ where condensation vanishes:

$$
h= \begin{cases}\left(\frac{\Delta t}{12}\right)\left[0.06\left(T_{d}-T_{a}\right)+R E\right] & \text { if } V<V_{0} \\ 0 & \text { if } V>V_{0}\end{cases}
$$

The quantity $R E$ is the available radiative energy, which depends on air water content (measured by the dew point temperature $T_{d}$, in ${ }^{\circ} \mathrm{C}$ ), site elevation $H$ (in $\mathrm{km}$ ) and cloud cover $N$ (in oktas):

$$
\begin{aligned}
& R E=0.37 \times\left(\begin{array}{l}
1+0.204323 H-0.0238893 H^{2}- \\
\left(18.0132-1.04963 H+0.21891 H^{2}\right) \times 10^{-3} T_{d}
\end{array}\right) \\
& \times\left(\frac{T_{d}+273.15}{285}\right)^{4}\left(1-\frac{\mathrm{N}}{8}\right)
\end{aligned}
$$

By filtering the rain and fog events and integrating the time series on a daily time-step corresponding to $h>0$, calculated daily yields and their cumulated values are obtained. We give an example of calculation in Appendix 1.

\subsection{Studied area}

The study area (Fig. 1) is characterized by a spatial extent of about $3000000 \mathrm{~km}^{2}$ between $15^{\circ}$ to $35^{\circ}$ south latitude and $13^{\circ}$ to $30^{\circ}$ for east longitude. In the following are detailed the different climate characteristics of the countries.
Namibia (824 $292 \mathrm{~km}^{2}$ surface area). The country shows three different climates, the most prevalent being semi-arid (Köppen-Geiger classification BSh) and hot desert (BWh). The less frequent is cold desert climates (BWk). The climate is characterized by great differences in day and nighttime temperatures, low rainfall and overall low humidity. Along the coast, the average annual precipitation does not exceed $15 \mathrm{~mm}$. Inside the country, the continental plateau has a more contrasted situation with abundant precipitations $(>500 \mathrm{~mm})$. The dry season, between May to October, correspond to little or no rainfall during July and August. Wildlife uses mainly waterholes and rivers when the water sources dry up. In desert areas, the average minimum temperature is cold and can fall below freezing at night. The wet season, between November to April, present daytime temperatures of about $30{ }^{\circ} \mathrm{C}$ with the first rains observed in November (mean rainfall $26 \mathrm{~mm}$ to a maximum in January with $91 \mathrm{~mm}$ ). Sometimes, torrential downpours are observed in the afternoon up to March and April, where rainfall decrease and stops before the dry season.

Botswana (581 $730 \mathrm{~km}^{2}$ surface area). The climate is characterized as hot semi-arid, the dominant climate (Köppen-Geiger classification BSh), and hot desert (BWh). During summer months (November-March), a rainy season is observed with high temperatures. The mean annual rainfall varies from over $650 \mathrm{~mm}$ in the extreme northeast area (Chobe District) to a minimum of $250 \mathrm{~mm}$ in the extreme southwest part (Kgalagadi District). The winter season during May to August corresponds to the dry season with less than $10 \%$ of the annual rainfall. The variability of rainfall increases while the quantity decreases toward the south and west.

South Africa (1.22 million $\mathrm{km}^{2}$ surface area). The country corresponds to a subtropical area, influenced by the vicinity of the oceans along the coastlines and the altitude of interior plateau (1 $500 \mathrm{~m}$ in the dolerite-capped Roggeveld scarp in the south-west, to a height of $3482 \mathrm{~m}$ in the KwaZulu-Natal Drakensberg). The country has several climatic zones depending on its geography: in the northwest, near the Atlantic coast stretching to the center of the country, the climate is mainly characterized by arid lime (BWh) or cold (BWk) deserts. In the south-east, the country offers a temperate climate with dry and hot (Csa) or warm (Csb) summers. Finally, along the southern coast of the country, one finds a hot (BSh) or cold (BSk) arid climate with steppes but also a temperate zone, along the ocean between the towns of George and Port Elisabeth with dry winters and hot summers (Cwa). The eastern part of the country, which is more mountainous, is characterized by a predominantly temperate climate, without a dry season, with hot to temperate $(\mathrm{Cfb})$ or cold $(\mathrm{Cfc})$ summers. Mean rainfall is about $460 \mathrm{~mm}$ with a large dispersion according to the location. Usually, the western Cape presents major rainfalls in winter whereas the rest of the country exhibits summer rainfalls.

The spatial distribution of rainfall between Namibia, Bostwana and South Africa presents some differences in space and time (New et al., 2000). In Namibia, for the locations of Dante Cave at the north of the country, summer rainfall is observed from October to April, with mean annual rainfall between 500 and $600 \mathrm{~mm} \mathrm{yr}^{-1}$, a value much less than the potential evapotranspiration estimated to $2900 \mathrm{~mm} \mathrm{yr}^{-1}$ (Railsback et al., 2019). A similar behavior is observed at the frontier between Bostwana and South Africa $\left(27^{\circ} \mathrm{S}, 21^{\circ} \mathrm{E}\right)$, with summer rainfall. The situation is more complex in South Africa. According to the location, one observes winter rainfall as in Cape Town with precipitations mainly during April to September, weak precipitations but year-round in George and summer rainfall with a dry winter in Pretoria (Railsback et al., 2019). 

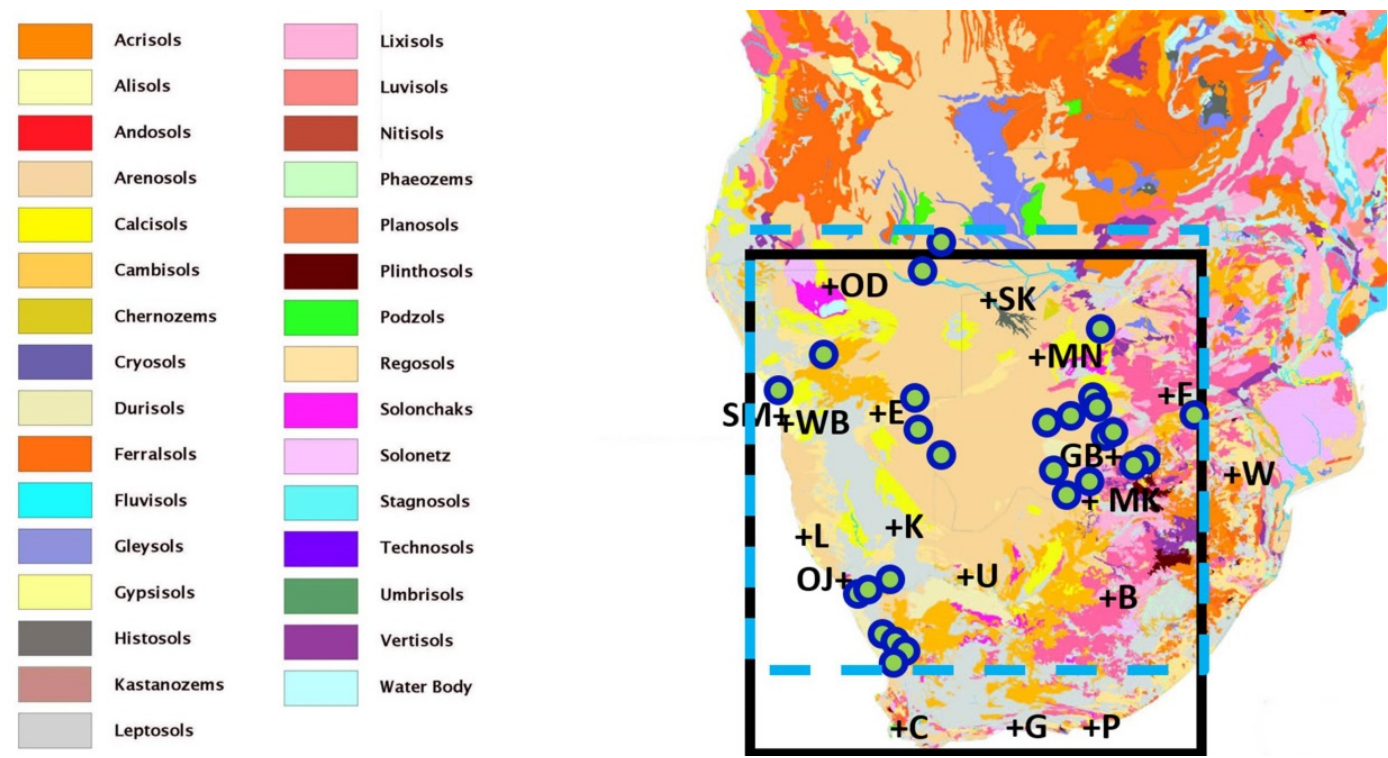

Fig. 1. Map of soils in the studied area (from Jones et al., 2013). Black rectangle and black letters are airport stations. The interrupted blue rectangle corresponds to the biocrust sites (green circles, see Chen et al., 2020).

Table 1. Sites where atmospheric data are collected ( 7 stations in Namibia, 4 stations in Bostwana and 7 stations in South Africa). They are sorted according to their longitude (west to east). The sky condition data availability ( $\%$ of the total sky conditions data) is reported for each station.

\begin{tabular}{|c|c|c|c|c|c|c|c|c|}
\hline $\begin{array}{l}\text { Country } \\
\text { Name }\end{array}$ & Site & Abbreviations & Latitude & Longitude & $\begin{array}{l}\text { Altitude } \\
\text { (m asl) }\end{array}$ & $\begin{array}{c}\text { Distance to } \\
\text { the sea }(\mathrm{km})\end{array}$ & $\begin{array}{l}\text { data } \\
\text { period }\end{array}$ & $\begin{array}{c}\text { Sky conditions } \\
\text { data (\%) }\end{array}$ \\
\hline Namibia & Swakopmund & SM & $22^{\circ} 40^{\prime} 0^{\prime \prime} \mathrm{S}$ & $14^{\circ} 34^{\prime} 0^{\prime \prime} \mathrm{E}$ & 61 & 8 & $2010-2020$ & 52.4 \\
\hline Namibia & Walvis Bay & WB & $22^{\circ} 58^{\prime} 47^{\prime \prime} \mathrm{S}$ & $14^{\circ} 38^{\prime} 43^{\prime \prime} \mathrm{E}$ & 86 & 14 & $2010-2020$ & 52.4 \\
\hline Namibia & Luderitz & $\mathrm{L}$ & $26^{\circ} 41^{\prime} 15^{\prime \prime} \mathrm{S}$ & $15^{\circ} 14^{\prime} 34^{\prime \prime} \mathrm{E}$ & 131 & 1 & $2006-2020$ & 0.0 \\
\hline Namibia & Ondangwa & OD & $17^{\circ} 52^{\prime} 41^{\prime \prime} \mathrm{S}$ & $15^{\circ} 57^{\prime} 09^{\prime \prime} \mathrm{E}$ & 1099 & 385 & 2011-2020 & 47.7 \\
\hline Namibia & Oranjemund & OJ & $28^{\circ} 35^{\prime} 05^{\prime \prime} \mathrm{S}$ & $16^{\circ} 26^{\prime} 48^{\prime \prime} \mathrm{E}$ & 5 & 6 & $2005-2020$ & 0.0 \\
\hline Namibia & Eros & $E$ & $22^{\circ} 36^{\prime} 44^{\prime \prime} \mathrm{S}$ & $17^{\circ} 04^{\prime} 50^{\prime \prime} \mathrm{E}$ & 1699 & 266 & $2011-2020$ & 45.2 \\
\hline Namibia & Keetmanshoop & K & $26^{\circ} 32^{\prime} 13^{\prime \prime} \mathrm{S}$ & $18^{\circ} 06^{\prime} 40^{\prime \prime} \mathrm{E}$ & 1069 & 285 & 2011-2020 & 40.0 \\
\hline South Africa & Cape Town & C & $33^{\circ} 58^{\prime} 10^{\prime \prime} \mathrm{S}$ & $18^{\circ} 35^{\prime} 50^{\prime \prime} \mathrm{E}$ & 46 & 3 & $2001-2020$ & 100.0 \\
\hline South Africa & Upington & $U$ & $28^{\circ} 24^{\prime} 04^{\prime \prime} \mathrm{S}$ & $21^{\circ} 15^{\prime} 35^{\prime \prime} \mathrm{E}$ & 844 & 432 & $2001-2020$ & 77.3 \\
\hline Botswana & Shakawe & SK & $18^{\circ} 22^{\prime} 25^{\prime \prime} \mathrm{S}$ & $21^{\circ} 50^{\prime} 00^{\prime \prime} \mathrm{E}$ & 1008 & 895 & $2005-2020$ & 100.0 \\
\hline South Africa & George & G & $34^{\circ} 0^{\prime} 20^{\prime \prime} \mathrm{S}$ & $22^{\circ} 22^{\prime} 42^{\prime \prime} \mathrm{E}$ & 197 & 7 & $2001-2020$ & 89.9 \\
\hline Botswana & Maun & $\mathrm{MN}$ & $19^{\circ} 59^{\prime} 0^{\prime \prime} \mathrm{S}$ & $23^{\circ} 26^{\prime} 0^{\prime \prime} \mathrm{E}$ & 945 & 1106 & $2001-2020$ & 100.0 \\
\hline South Africa & Mahikeng & MK & $25^{\circ} 48^{\prime} 27^{\prime \prime} \mathrm{S}$ & $25^{\circ} 32^{\prime} 40^{\prime \prime} \mathrm{E}$ & 1274 & 680 & $2001-2020$ & 65.6 \\
\hline South Africa & Port Elizabeth & $P$ & $33^{\circ} 59^{\prime} 5^{\prime \prime} \mathrm{S}$ & $25^{\circ} 37^{\prime} 2^{\prime \prime} \mathrm{E}$ & 68 & 3 & $2001-2020$ & 100.0 \\
\hline Botswana & Gaborone & GB & $24^{\circ} 33^{\prime} 19^{\prime \prime} \mathrm{S}$ & $25^{\circ} 55^{\prime} 06^{\prime \prime} \mathrm{E}$ & 1006 & 695 & $2001-2020$ & 99.9 \\
\hline South Africa & Bram Fischer & $B$ & $29^{\circ} 05^{\prime} 38^{\prime \prime} \mathrm{S}$ & $26^{\circ} 18^{\prime} 14^{\prime \prime} \mathrm{E}$ & 1349 & 418 & $2001-2020$ & 76.1 \\
\hline Botswana & Francistown & $\mathrm{F}$ & $21^{\circ} 10^{\prime} 0^{\prime \prime} \mathrm{S}$ & $27^{\circ} 29^{\prime} 0^{\prime \prime} \mathrm{E}$ & 1002 & 726 & $2002-2020$ & 100.0 \\
\hline South Africa & Wonderboom & $\mathrm{W}$ & $25^{\circ} 39^{\prime} 13^{\prime \prime} \mathrm{S}$ & $28^{\circ} 13^{\prime} 27^{\prime \prime} \mathrm{E}$ & 1240 & 460 & $2005-2020$ & 88.6 \\
\hline
\end{tabular}

\subsection{Extraction data}

All ground stations are installed on international or national airports where standard meteorological parameters are measured. The meteorological stations meet the data measurement standards of the World Meteorological Organization. Air $T_{a}$ $\left({ }^{\circ} \mathrm{C}\right)$ and dew $T_{d}\left({ }^{\circ} \mathrm{C}\right)$ temperatures, relative humidity $(\mathrm{RH}, \%)$, atmospheric pressure $(P, \mathrm{~Pa})$ are measured in a meteorological shelter, $1.5 \mathrm{~m}$ from the ground. The windspeed $\left(V, \mathrm{~km} \mathrm{~h}^{-1}\right)$ and direction (sectors or degrees) are measured at $10 \mathrm{~m}$ from the ground. Note that wind speed can be extrapolated at any height $z$ above the ground by the classical logarithmic variation (see e.g. Pal Arya, 1988) $V(z)=V_{10} \ln \left(\frac{z}{z_{c}}\right) / \ln \left(\frac{10}{z_{c}}\right)$ where $V_{10}$ is windspeed at $10 \mathrm{~m}$ and $z_{c}$ is the roughness length (generally $\approx$
$0.1 \mathrm{~m}$ in flat areas) where $V=0$. Available data were extracted from the online data base "Weather Underground" (Weather Underground database, 2021) during a period of maximum 20 years (2001-2020) with a minimum of 10 years (2011-2020) depending on data availability (Table 1).

Dew yields have been computed from Eq. (2) using the above standard meteorological databases extracting air and dew point temperatures $\left(T_{a}\right.$ and $\left.T_{d},{ }^{\circ} \mathrm{C}\right)$, relative humidity ( $\left.\mathrm{RH}, \%\right)$, wind speed $\left(\mathrm{km} \mathrm{h}^{-1}\right.$ to be transformed in $\left.\mathrm{m} \mathrm{s}^{-1}\right)$, wind direction (sectors), absolute pressure ( $\mathrm{hPa}$ ) and sky cover. An hourly time-step for measured data is accessible except for Oranjemund and Luderitz (Namibia) where two time-steps are available (Oranjemund: $6 \mathrm{~h}$ on 2005-2014 and $3 \mathrm{~h}$ on 2014-2020); Luderitz ( 6 h on 2006-2012 and $3 \mathrm{~h}$ on 2012-2020).

Wind direction values in degrees have been computed from wind direction sectors (N, NNE, NE, E, ESE, SE, S, etc.) using 
a standard law of proportionality: $0^{\circ}$ for north, $180^{\circ}$ for south and calculation of all intermediate values with respect to these references.

The sky cover was considered variable if it varies by one or more of the reported values (CLR, FEW, SCT, BKN, or OVC) during the period of observation (NOAA's national weather service glossary, 2021). Cloud cover in oktas was computed from the nightly observation of sky cover using the correspondence listed in Table SM2 in Supplementary Materials, which was used in a previous work (Muselli et al., 2020). However, cloud cover is sometimes not available at night on some sites (the missing percentage of total values is noted for each site in Table 1). When the sky conditions data are unavailable, we imposed to these sites three possible values, corresponding to the most probable: $N=0,1$ and 3 .

Measured rainfall data, available on a daily time step, are extracted from the meteorological data base (Infoclimat database, 2021). All data are obtained for the same stations as used for dew calculation except for Swakopmund where the rainfall data of Walvis Bay are used (both sites are only $25 \mathrm{~km}$ apart).

\subsection{Kriging maps}

Kriging methodologies are mainly used for mapping spatial distribution of a given variable. The classical algorithm is presented in Appendix 2. Belkiri et al. (2020) use Kriging to study ground water composition. Tomaszkiewicz et al. (2016) propose ordinary Kriging to develop dew maps integrating projected climate changes in the Mediterranean basin. Martinez et al. (2017) present median polish Kriging (MPK) for space-time analysis of monthly precipitation in Colombia. Pue et al. (2021) introduce a Kriging-based Gaussian process for the evaluation for the prediction of soil water retention in tropical and temperate climates. Other studies combine Kriging models for the estimation of rainfall with Lagrangian (Amani and Lebel, 1997) or Bayesian (Lima et al., 2021) approaches.

\section{RESULTS}

\subsection{Evolution}

For each site, dew (subscript $i=d$ ) and rain (subscript $i=r$ ) monthly yields $h_{i}$ (mean, min, max in $\mathrm{mm}$ ) are computed. Annual dew yield (mm) is deduced by adding the monthly $h_{i}$ :

$$
H_{i}=\sum_{t=1}^{12} h_{i}(t)
$$

In order to estimate the evolution, monthly dew yields can be fitted by a linear regression on the measured period:

$$
h_{i}(t)=\alpha_{i} t+h_{i, 0}
$$

With $t$ in month, the coefficient $\alpha_{i}=d h_{i} / d t$ represents the monthly evolution rate.

\subsection{Dew yields \\ 3.2.1 Data description}

Mean, minimum and maximum dew yields are calculated on monthly and yearly time bases and reported in Table SM3 in Supplementary Materials. The calculated annual dew yields show significant variations depending on the sites studied even within the same country (Fig. 2 and Table SM3).

In Namibia, the sites on the west coast (Walvis Bay, Luder- itz, Swakopmund and Oranjemund) benefit from high dew yields $\left(>10 \mathrm{~mm} \mathrm{yr}^{-1}\right)$ mainly explained by the high humidity due to the vicinity of the Atlantic Ocean. For example, mean dew yields in the range 12.6 to $38.2 \mathrm{~mm} \mathrm{yr}^{-1}$ (for $N_{\text {missing }}=0,1$, 3) have been obtained in Swakopmund and Walvis Bay, located near the Namib national Park, corresponding to mean monthly dew yields between 2.8 and $6.9 \mathrm{~mm}$. For both stations, dewy days represent between 79.1 (Swakopmund, $N=3$ ) and $85.8 \%$ (Walvis Bay, $N=0$ ) of the year. On the other hand, the stations established in the interior of the country suffer from very low annual dew yield $\left(<5 \mathrm{~mm} \mathrm{yr}^{-1}\right)$. For example, Eros, Keetmanshoop and Ondangwa, respectively located at about 250 and $350 \mathrm{~km}$ from the ocean, exhibit annual dew yields less than $4.9 \mathrm{~mm}$. In Keetmanshoop, monthly dew yields are very weak with a mean of $0.1-0.3 \mathrm{~mm}$ and a monthly maximum of up to $1.8 \mathrm{~mm}$. For Eros and Keetmanshoop, only $10-20 \%$ of the days are dewy $(\min =8.7 \%$ and $\max =18.4 \%)$, while for Ondangwa it is $25 \%$ or even $15 \%$ ( $N=0$ for missing data) or even one day a week in the most unfavorable case $(N=3$ for missing data).

The situation is more homogeneous in Botswana. The mean annual dew yields are between 6.9 and $16.2 \mathrm{~mm}$ depending on the sites (annual dew yield $\min =1.8-6.6 \mathrm{~mm}$ and $\max =16.5-$ $26 \mathrm{~mm}$ ), with monthly yields averaging between 0.6 and 1.4 $\mathrm{mm}(\mathrm{min}=0 \mathrm{~mm}$ and $\max =4.2-5.9 \mathrm{~mm})$.

Except in Upington (mean $<5.5 \mathrm{~mm}$ ), located in the northern Cape Province of South Africa on the banks of the Orange River, and Mahikeng, near to the Bostwana frontier (mean < $9.8 \mathrm{~mm}$ ), all the South Africa country exhibits mean annual dew yields more than $15 \mathrm{~mm}$. For example, Cape Town, Port Elizabeth and George cities, on the south coast, or Wonderboom and Bram Fischer (near respectively Pretoria and Johannesburg), present averaged annual dew yields of more than $18.3 \mathrm{~mm}$, and up to $27 \mathrm{~mm}$. Whereas the maximum monthly dew yields do not exceed $4.7 \mathrm{~mm}$ in Upington and Mahikeng, the other cities present monthly dew yields larger than $4.5 \mathrm{~mm}$, and up to $7.7 \mathrm{~mm}$.

The spatial distribution of dew yields was determined by Kriging (Fig. 2, for $N=0,1,3$ for missing data). Maps of mean annual dew yields are presented in (Figs. 2a, b, c). As expected and described in the literature (Henschel et al., 2007; Soderberg, 2010), dew exhibits the highest yields along the west coast of Namibia corresponding to the Namib Desert. This desert represents about $81000 \mathrm{~km}^{2}$ and stretches over $1,500 \mathrm{~km}$ along an 80 to $160 \mathrm{~km}$ wide north-south coastal strip along the Atlantic Ocean. One also clearly observes the decrease in yields inland, especially from the central plateau towards the desert of Kalahari representing a surface of $900000 \mathrm{~km}^{2}$ with 600000 $\mathrm{km}^{2}$ in Namibia. However, one notes that in these critical areas, monthly dew yields can reach mean and maximal values up to 2-3 $\mathrm{mm}$ and 6-8 $\mathrm{mm}$, respectively. Note that the biocrust sites are located in regions of moderate dew yield.

More generally, there is a tendency to see a decrease in dew yield with increasing distance from the oceans, located $\mathrm{W}, \mathrm{E}$ and $\mathrm{S}$. A clear decrease in nocturnal $\mathrm{RH}$ from west to east is obvious (Fig. 2d), with the largest dew yields (Fig. 2a, b, c) corresponding to the regions of highest RH.

\subsubsection{Evolution map 2001-2020}

In Fig. SM1 (Supplementary Materials) are plotted the evolution of the summed value of dew yield, $\operatorname{sum}\left(h_{d}\right)=\int^{t} h_{d} d t$ $t_{0}$

on a monthly basis, with $t_{0}$ the starting year (see Table 1 ). The dew rate is either nearly constant during the period 

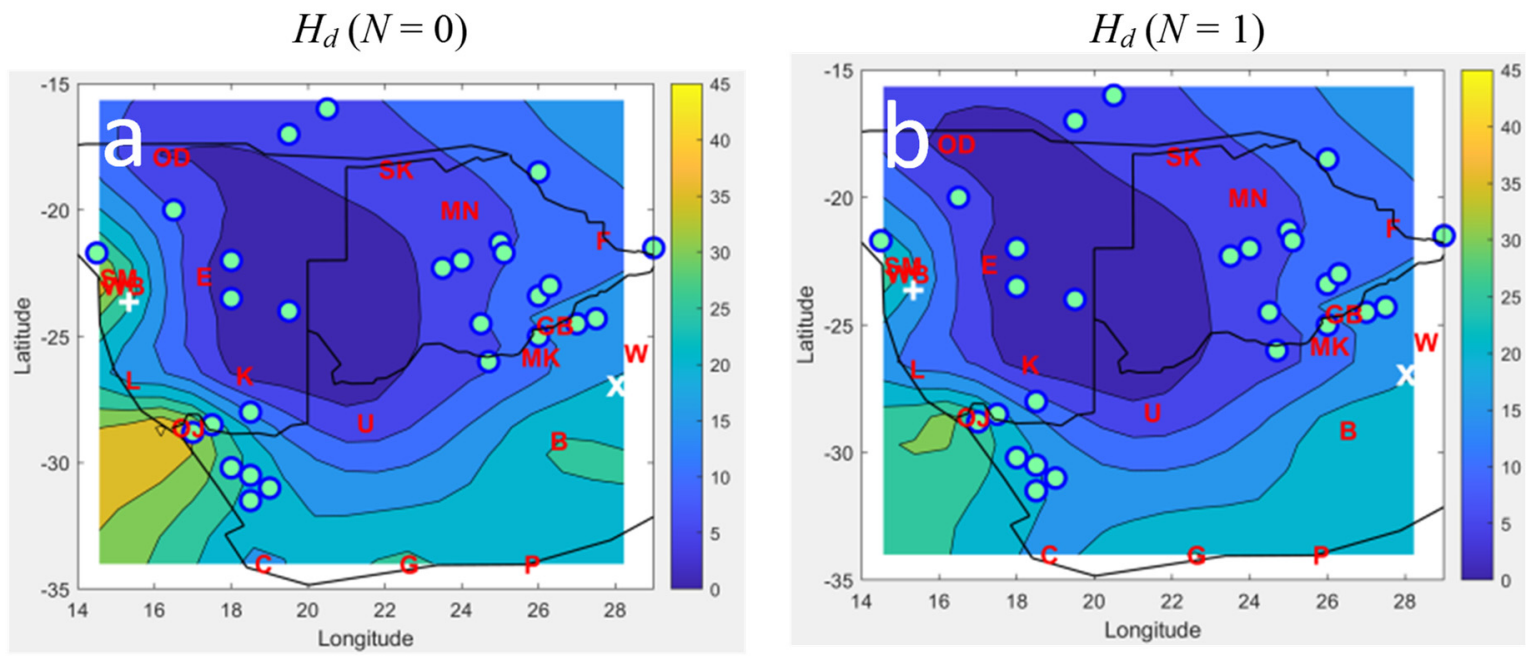

$$
H_{d}(N=3)
$$

\section{$\mathrm{RH}$}
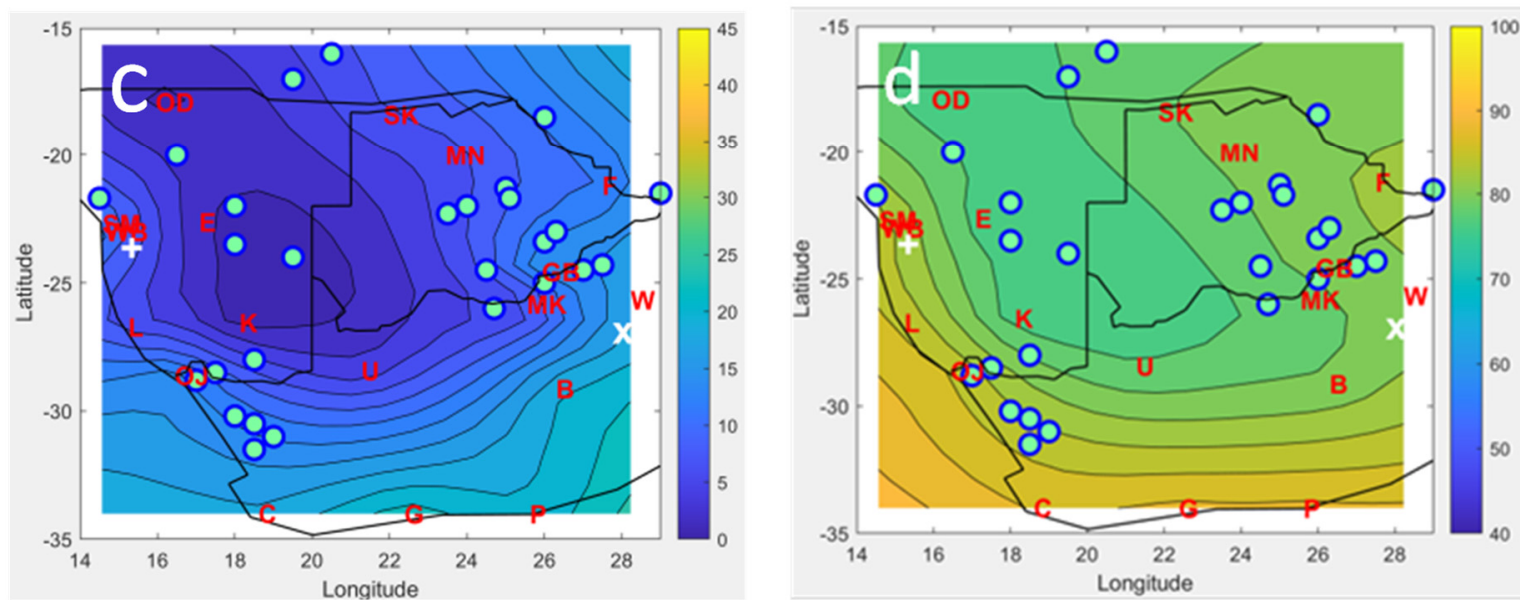

Fig. 2. (a, b, c): Map of annual dew yield $H_{d}$ (in mm) in the period 2001-2020 corresponding to three scenarios for missing $N$ data (see text and Table 1). (d): Mean nocturnal RH (\%) during dew events. Red letters: Meteo sites (see Table 1); circles: Biocrust sites according to Chen et al. (2020); right cross: Gobabeb site studied by Henschel et al. (2007) and Soderberg (2010); inclined cross: Potchefstroom site studied by Baier (1966).

$N=0$

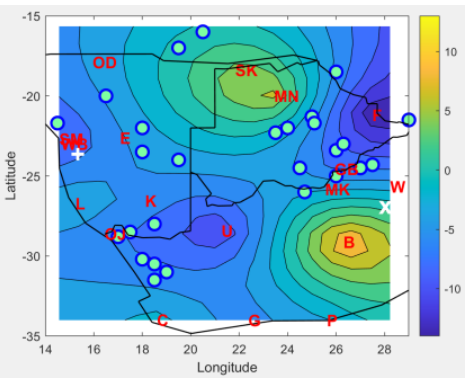

$N=1$

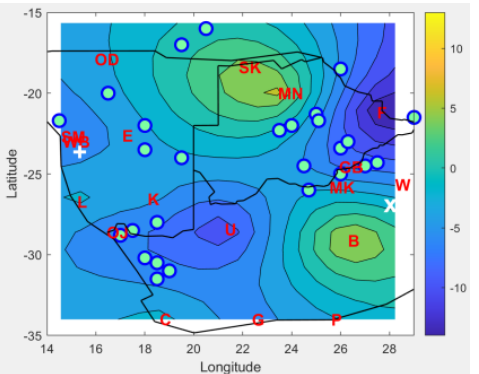

$N=3$

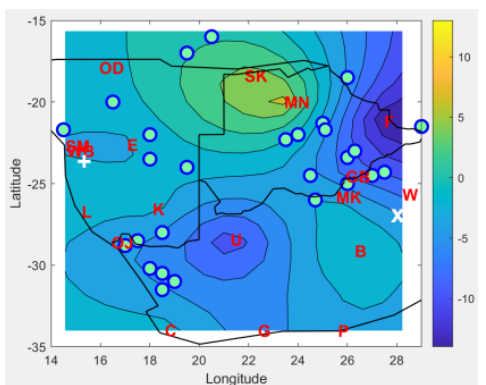

Fig. 3. Difference between 2020 and 2011 annual dew yields $(\mathrm{mm})$ for three scenarios corresponding to the missing $N$ data (see text and Table 1). Red letters: Measurement sites (see Table 1); circles: biocrust sites according to Chen et al. (2020); right cross: Gobabeb site studied by Henschel et al. (2007) and Soderberg (2010); inclined cross: Potchefstroom site studied by Baier (1966).

(Swakopmund, Walvis Bay, Eros, Keetmanshoop, Cape Town, Port Elizabeth, Gaborone, Bram Fischer) or increases (Luderitz, Oranjemund, Upington, Shakawe, George, Maun, Mahikeng, Wonderboom) after year 2010. One will see in Section 3.3 that the year 2010 is also the year where rainfalls significantly decrease.
By considering the period where meteorological data are available on all sites (2011-2020), one can determine the evolution of the average yield at any point in the study area by subtracting annual dew yields between years 2020 and 2011. Figure 3 shows the difference $\Delta h_{d}=h_{d}(2020)-h_{d}(2011)$. One sees that the evolution is different according to the locations. 
Although dew decreases in two places where it was the most abundant (SW and NE to a lesser extent), it increases in the NW (Ondangwa, Eros) where dew was the lowest. A noticeable increase is seen in $N$ (Maun, Shakawe) and SE regions (Bram Fischer). One notes that the biocrust sites are mostly located in regions of null or moderate dew decrease.

\subsection{Rainfall}

\subsubsection{Data description}

Table 2 and Fig. 4 present annual and monthly mean, min and max rainfall extracted from Infoclimat database (2021) for the studied period (sites: See Table 1). From a general point of view, rain decreases towards $\mathrm{W}$ and $\mathrm{N}$. As described below, cities located at the Namib Desert exhibit lower rain precipitations: $13.4 \mathrm{~mm}$ in Swakopmund and Walvis Bay (i.e. 1\% of rainfall events by year) and in a lesser extent, Oranjemund with a mean annual rainfall of about $42 \mathrm{~mm}$ (i.e. $5 \%$ of rainfall events by year). In these areas, precipitations are very erratic, with no rain for several months and few intense precipitations events. In the inland, rainfall is slightly more abundant with annual averages of 115, 189 and $306 \mathrm{~mm}$ for Keetmanshoop, Ondangwa and Eros, respectively. Although these areas can exhibit months without any rain, the monthly averages are greater than $10 \mathrm{~mm}$. However, one notes that less than $11 \%$ of the days of the year are rainy days $(10.9 \%, 5.3 \%$ and $3.7 \%$ in Eros, Ondangwa and Keetmanshoop, respectively).

For Botswana, the situation is more homogenous, with a mean rainfall of $463.2 \mathrm{~mm}$ observed in the four cities of Gaborone, Maun, Francistown and Shakawe. With one or two months during the year without rain, this region present mean regular monthly rainfall of about $39 \mathrm{~mm}$, with $13.4 \%$ of the days being rainy.

South Africa exhibits a contrasted behavior. The regions located along the ocean in the south and south east of the country have heavy rainfall with annual amounts greater than $500 \mathrm{~mm}$ (Mahikeng, Cape Town, George, Port Elizabeth, Bram Fischer, Wonderboom), with up to $715 \mathrm{~mm}$ in George (18-31\% of the year are rainy days). Monthly averages are important with a mean of about $49.6 \mathrm{~mm}(23.5 \%$ rainy days in the year). Upington is an exception, located further west of the country, but with lower rainfall $\left(285 \mathrm{~mm}\right.$ year $^{-1}$ with a mean of 23.8 mm month ${ }^{-1}$ ).

One notes a marked decrease in precipitation during the 20 years period, all sites show $\alpha\left(h_{r}\right)<-0.2$, particularly in Eros and Ondangwa in Namibia, the 4 cities of Bostwana, and George and Bram Fisher in South Africa. Coastal sites in Namibia (Oranjemund, Luderitz, Swakopmund and Walvis Bay) show a smaller decrease $\left(\alpha\left(h_{r}\right) \approx 0\right)$. When looking at Fig. SM1 in Supplementary Materials (summed values of $h_{r}$ ), one realizes that the main change in rainfalls occurred in 2010 . It is from this year that a gradual change in rain can be observed.

The rainfall repartition presented in Table 2 is confirmed by the Kriging map obtained for the annual mean rainfall (Fig. 4a). Rainfall increases markedly from west to east $(0-200 \mathrm{~mm}$ at the Atlantic coast to 600 to 700 measured at the south-east of South Africa). The same trend is observed with the monthly mean and maximum rainfall volumes (Figs. $4 \mathrm{~b}, \mathrm{c}$ ). The monthly average varies from 0 to $20 \mathrm{~mm}(\mathrm{~W})$ to 50 to $60 \mathrm{~mm}(\mathrm{SE})$.

\subsubsection{Evolution map}

By subtracting the precipitation values between years 2020 and 2011 one can map (Fig. 5) the difference $\Delta h_{r}=h_{r}(2020)$ $h_{r}(2011)$. Although the mean precipitation decreases, the evolution is different depending on the locations. Rain mainly decreases in the north regions (Maun, Shakawe, Eros), where dew was seen to increase during the same time period (Fig. 3). A small zone in south west (Cape Town, Oranjemund) exhibits a precipitation increase. It is worthy to note that the biocrust zones are mostly in the regions that experienced a decrease in rain.

\subsection{Correlation between dew and rain yields}

The occurrence of dew is related to the presence of atmospheric high humidity. Some correlations therefore exist between the frequency and amplitude of rain and the amplitude of dew yields. Two kinds of correlation can occur, a temporal correlation, where dew forms after rain events, which have increased the atmosphere $\mathrm{RH}$, and an amplitude correlation. Both correlations are studied in the following.

Table 2. Mean, minimum and maximum yearly $\left(H_{r}\right)$ and monthly $\left(h_{r}\right)$ rainfall calculated from meteorological from 2001 to 2020 are fitted to Eq. (5) with free parameters $\alpha_{r}=d h_{r} / d t$ and $h_{r, 0}$.

\begin{tabular}{|c|c|c|c|c|c|c|c|c|c|}
\hline \multirow{2}{*}{ Site } & \multicolumn{3}{|c|}{$H_{r}\left(\mathrm{~mm} \mathrm{yr}^{-1}\right)$} & \multicolumn{3}{|c|}{$h_{r}(\mathrm{~mm})$} & \multirow{2}{*}{$\begin{array}{c}\alpha_{r} \\
\left(\mathrm{~mm} \mathrm{month}^{-1}\right)\end{array}$} & \multirow{2}{*}{$\begin{array}{c}h_{r, 0} \\
(\mathrm{~mm})\end{array}$} & \multirow{2}{*}{$\begin{array}{c}\text { year } \\
\text { frequency } \\
(\%)\end{array}$} \\
\hline & Mean & Min & Max & Mean & Min & Max & & & \\
\hline Swakopmund & 13.4 & 0.0 & 56.0 & 1.1 & 0.0 & 41.2 & -0.005 & 1.5 & 0.9 \\
\hline Walvis Bay & 13.4 & 0.0 & 56.0 & 1.1 & 0.0 & 41.2 & -0.005 & 1.5 & 0.9 \\
\hline Luderitz & 18.6 & 1.0 & 83.5 & 12.4 & 0.0 & 64.1 & -0.024 & 3.2 & 1.8 \\
\hline Ondangwa & 189.4 & 6.6 & 453.0 & 15.8 & 0.0 & 155.0 & -0.283 & 32.9 & 5.3 \\
\hline Oranjemund & 42.2 & 7.0 & 225.8 & 3.5 & 0.0 & 115.6 & -0.030 & 6.4 & 5.0 \\
\hline Keetmanshoop & 115.7 & 20.8 & 278.4 & 9.6 & 0.0 & 145.1 & -0.044 & 11.0 & 3.7 \\
\hline Cape Town & 542.1 & 249.0 & 888.8 & 45.2 & 0.0 & 238.0 & -0.148 & 57.0 & 24.8 \\
\hline Upington & 285.1 & 53.0 & 518.4 & 23.8 & 0.0 & 261.4 & -0.167 & 38.3 & 10.4 \\
\hline Shakawe & 423.5 & 8.4 & 1072.3 & 35.3 & 0.0 & 447.1 & -0.493 & 82.8 & 13.0 \\
\hline George & 715.4 & 333.0 & 1223.7 & 59.6 & 0.0 & 290.5 & -0.260 & 79.7 & 30.7 \\
\hline Maun & 482.8 & 20.0 & 1115.9 & 40.2 & 0.0 & 375.3 & -0.468 & 79.8 & 14.9 \\
\hline Mahikeng & 582.8 & 182.0 & 1158.1 & 48.6 & 0.0 & 320.3 & -0.135 & 55.5 & 19.7 \\
\hline Port Elizabeth & 641.8 & 308.0 & 1103.8 & 53.5 & 0.0 & 235.5 & -0.171 & 64.2 & 26.8 \\
\hline Gaborone & 464.3 & 80.2 & 1023.3 & 38.7 & 0.0 & 372.5 & -0.374 & 68.0 & 11.9 \\
\hline Bram Fischer & 590.0 & 160.0 & 1190.0 & 49.2 & 0.0 & 274.7 & -0.253 & 68.8 & 20.2 \\
\hline Francistown & 482.3 & 46.2 & 1199.9 & 40.2 & 0.0 & 423.3 & -0.342 & 66.2 & 13.6 \\
\hline Wonderboom & 497.5 & 123.0 & 769.9 & 41.5 & 0.0 & 183.6 & -0.095 & 49.9 & 18.5 \\
\hline
\end{tabular}



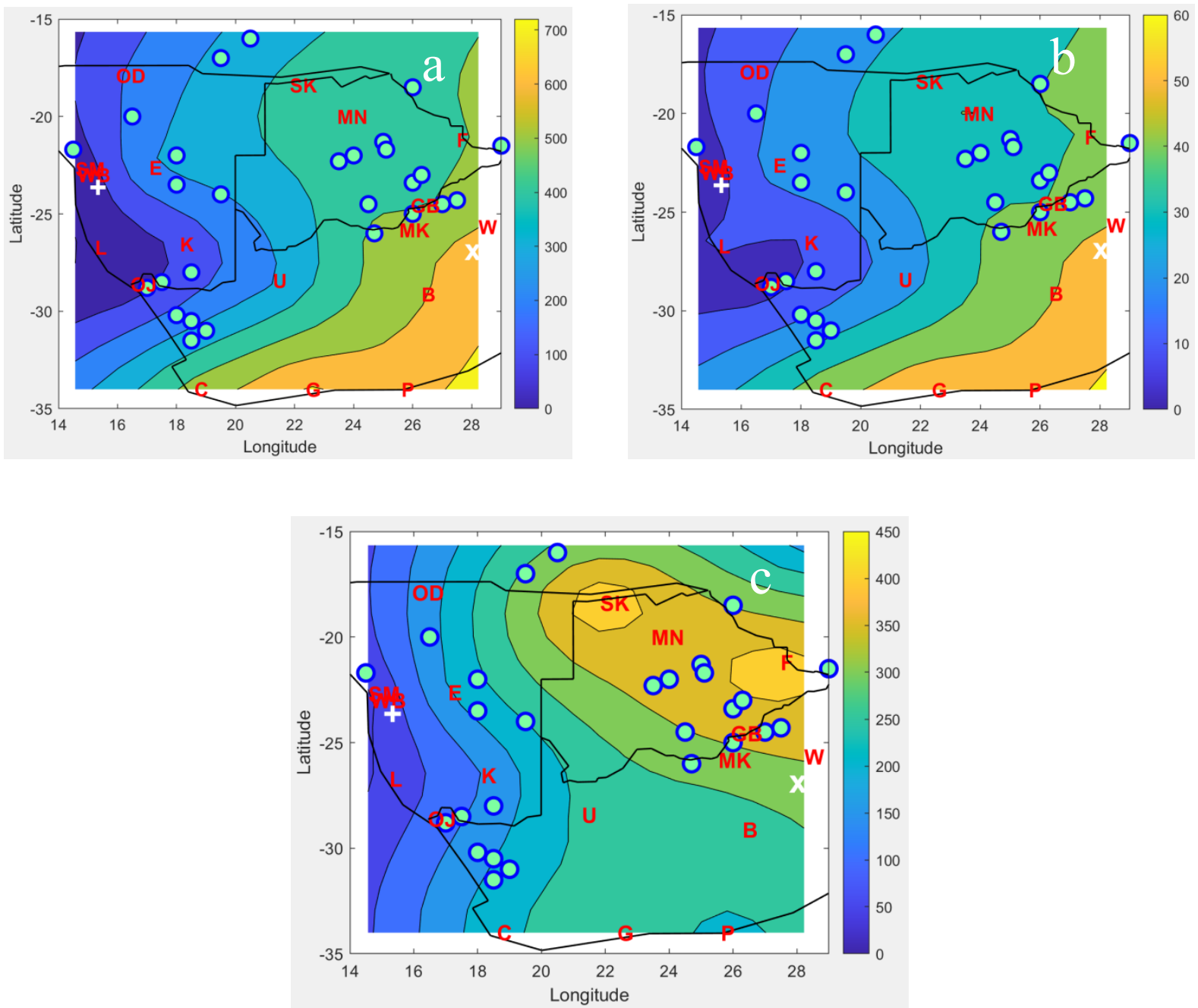

Fig. 4. Mean rainfalls (mm) during the period 2001-2020. (a) Mean annual rainfall. (b) Mean monthly rainfall. (c) Maximum monthly rainfall. Red letters: Measurement sites (see Table 1); circles: biocrust sites according to Chen et al. (2020); right cross: Gobabeb site studied by Henschel et al. (2007) and Soderberg (2010); inclined cross: Potchefstroom site studied by Baier (1966).

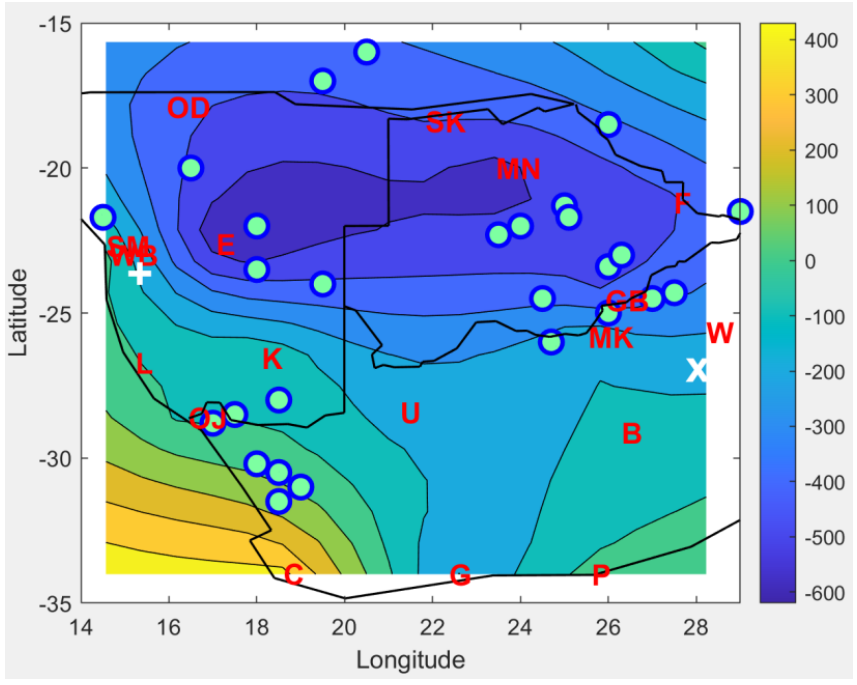

Fig. 5. Difference between 2020 and 2011 of the annual rainfalls $(\mathrm{mm})$. Red letters: Measurement sites (see Table 1); circles: biocrust sites from Chen et al. (2020); right cross: Gobabeb site studied by Henschel et al. (2007) and Soderberg (2010); inclined cross: Potchefstroom site studied by Baier (1966).

\subsubsection{Temporal correlation}

The temporal correlation between rainfall and dew yield is evaluated by a correlation coefficient $r$ between the daily rainfall, $h_{r}(t)$, and the time-shifted daily dew yield, $h_{d}(t+\tau)$, estimated at the same location. The delay time $\tau$ corresponds to the previous and next days of time $t$ and is counted in days in the interval $[-31,+31]$. The covariance between $h_{d}(t+\tau)$ and $h_{r}(t)$ is calculated as:

$$
C\left[h_{r}(t), h_{d}(t+\tau)\right]=\frac{1}{n} \sum_{j=1}^{n}\left(h_{r, j}(t)-\overline{h_{r}}\right)\left(h_{d, j}(t+\tau)-\overline{h_{d}}\right)
$$

With $\sigma_{h_{r}}, \sigma_{h_{d}}$ the rain and dew standard deviation, respectively, one infers the correlation coefficient:

$r\left[h_{r}(t), h_{d}(t+\tau)\right]=\frac{C\left[h_{r}(t), h_{d}(t+\tau)\right]}{\sigma_{h_{r}} \sigma_{h_{d}}}$

Considering that $-1<r<1$, a negative correlation leads to an opposite evolution of $h_{r}$ and $h_{d}$, a positive correlation corresponds to the two variables moving in the same trend and $r \rightarrow 0$ means that both variables are not correlated. 
The $r$ correlation plots for each meteorological site according to the three $N$ scenarii are reported in Fig. 6. One observes the following:

(i) For $\tau<0$, no correlations between dew and rain amplitudes are observed (mostly $r<0.05$ ). It means that a rain event at a given day does not explain dew events a few days earlier.

(ii) For $\tau=0$, all curves present negative values for $r$, with amplitude in the range between -0.3 and 0.1 . This is due to the fact that, in the calculation of the dew yields in Section 2.1, one had to discard the days with rain.
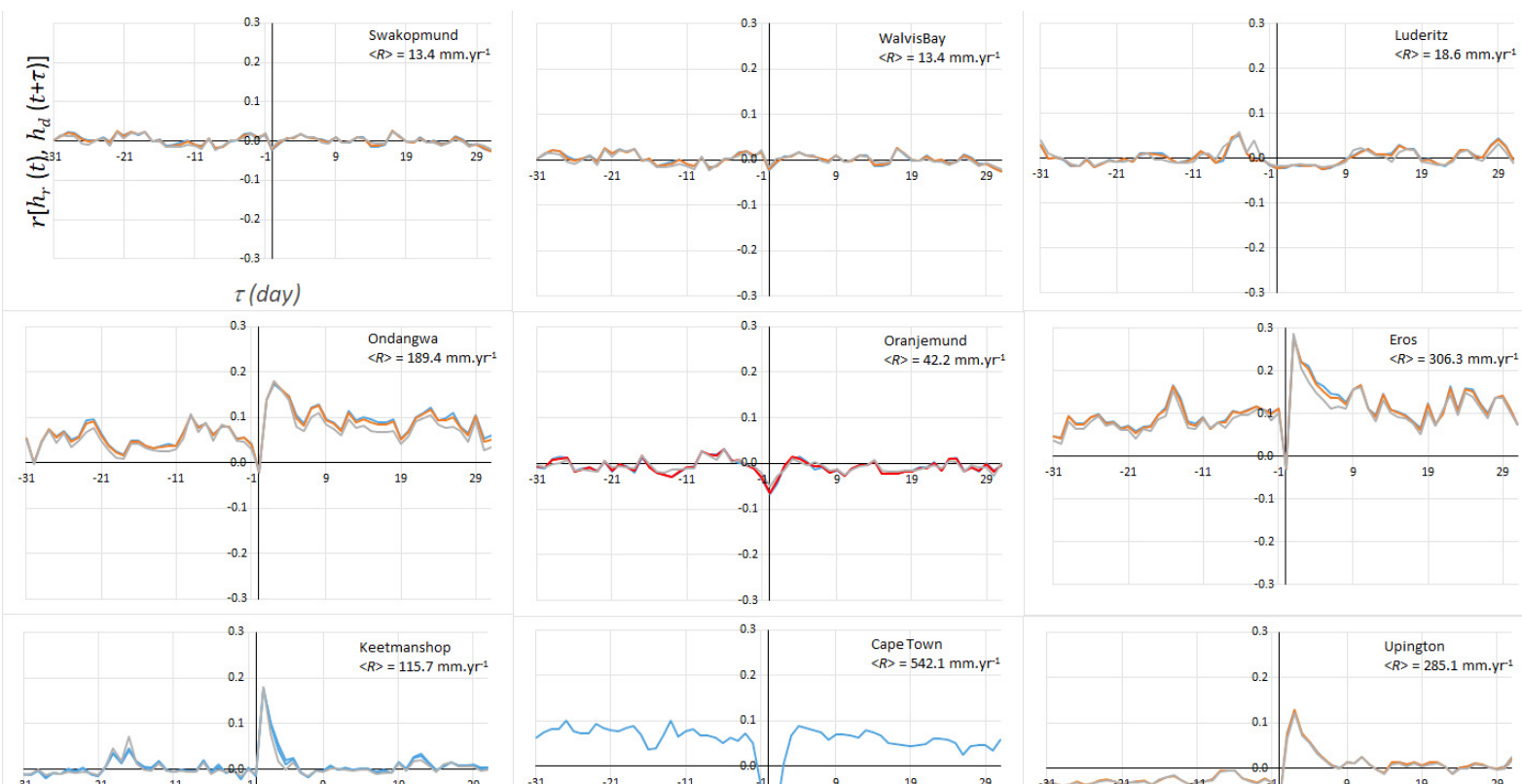

days. For the Eros and Keetmanshop sites, $r=0.29(N=3)$ and $r=0.18(N=1)$. For Mahikeng and Upington, $r=0.12(N=1)$ and $r=0.13(N=0)$. To a lesser extent, for Bram Fischer $r=0.097$ for $N=1$. These values thus indicate a weak but real positive correlation between rain and dew events. It means that, due to the increase of atmosphere humidity after rain events, dew events are more likely to be observed between one to three days after rainfalls.

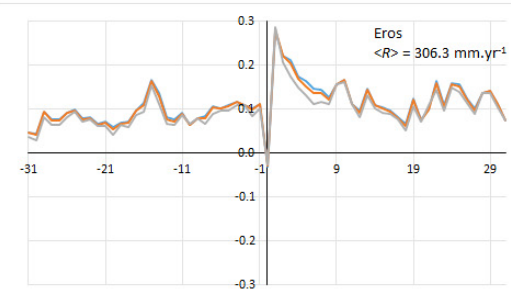

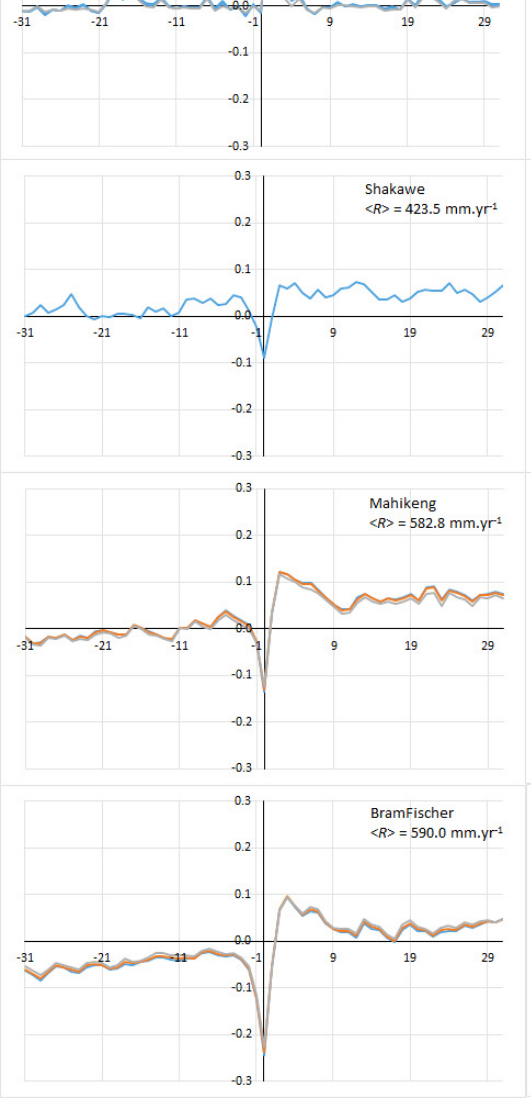
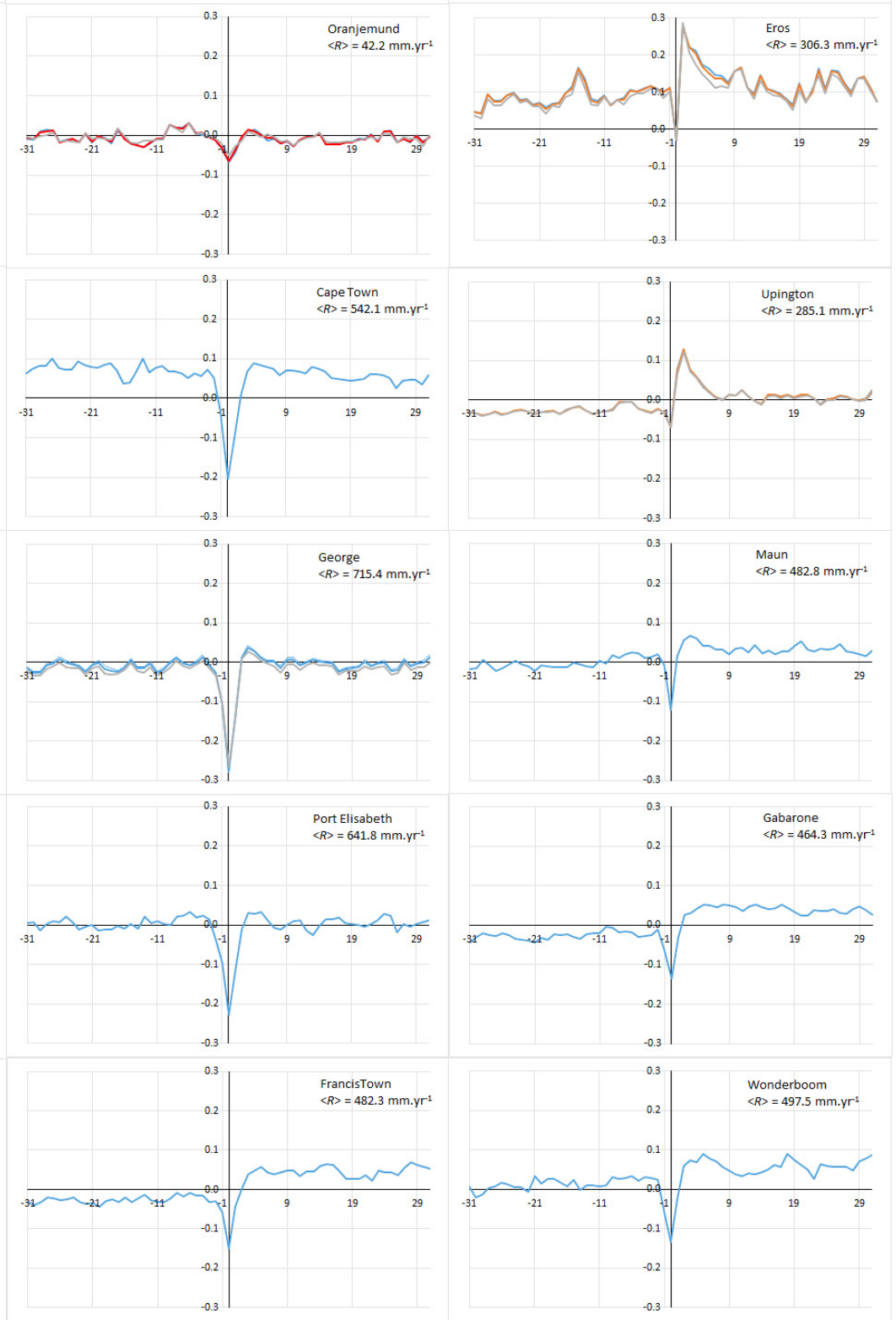

Fig. 6. Daily correlation coefficients $r\left[h_{r}(t), h_{d}(t+\tau)\right]$ for time $\tau \epsilon[-31-+31]$ days. For stations with incomplete cloud cover data, the curves are presented assuming $N=0$ (blue), $N=1$ (red) and $N=3$ (grey). 
The correlation dew-rain is most noticeable (Ondangwa, Eros, Keetmanshop; Upington, Mahikeng, Bram Fisher) when the distance from the ocean increases, the atmosphere $\mathrm{RH}$ then decreases (see Fig. 2d). In contrast, for stations close to the coast in arid climate (distance $<15 \mathrm{~km}$ ) and with low annual rainfall $\left(H_{r}<50 \mathrm{~mm}\right)$ but large $\mathrm{RH}$, such as Luderitz, Oranjemund, Swakopmund and Walvis Bay, the correlation is very low regardless of the $\tau$ value. For the cities of Cape Town, Port Elizabeth and George, presenting a more temperate climate, the correlation shows at most a weak increase for $\tau<4$ to 5 days (with $r<0.1$ ). All these sites have an altitude below $200 \mathrm{~m}$.

Whatever is the $N$ scenario, for altitudes between $800 \mathrm{~m}$ and $1700 \mathrm{~m}$ asl and $>200 \mathrm{~km}$ away from the ocean, the correlation is clearer with values of $r$ showing a steady increase at Eros (1700 m asl, $266 \mathrm{~km}$ from the ocean), Keetmanshoop (1069 m asl, $285 \mathrm{~km}$ from the ocean). Ondangwa (1099 m asl, $385 \mathrm{~km}$ from the ocean) and Bram Fischer (1349 $\mathrm{m}$ asl, $418 \mathrm{~km}$ from the ocean) show a correlation with $r>0.1$, respectively for $\tau=$ 2 and 3. For the other mountainous stations, the correlation coefficients exhibit values that does not exceed 0.1 , with $\tau=5$ for Gaborone $(r=0.0532)$ or $\tau=3$ for Maun $(r=0.0665)$.

\subsubsection{Summed dew and rain yields}

One now investigates the correlation between the cumulative dew and rain monthly yields, $\operatorname{sum}\left(h_{d}\right)=\int_{t_{0}}^{t} h_{d} d t$ and $\operatorname{sum}\left(h_{r}\right)=\int_{t_{0}}^{t} h_{r} d t$, respectively, with $t_{0}$ the starting time (see Table 1). Each data point will thus correspond to a monthly mean value. For each month, a ratio $a(t)$ is calculated:

$$
a(t)=\frac{\left[\operatorname{sum}\left(h_{d}\right)\right]_{t}}{\left[\operatorname{sum}\left(h_{r}\right)\right]_{t}}
$$

In Fig. 7a the $\operatorname{sum}\left(h_{d}\right)$, the $\operatorname{sum}\left(h_{r}\right)$ and their ratio $a(t)$ for two sites (Upington and Cape Town sites) are reported (at small times the dispersion is large because the smoothing effect of the summation is still weak). In Cape Town, both rain and dew amounts are nearly linear during the research period, with a decrease in rainfall rate after 2010 while the dew rate remains constant. In Upington, one observes a decrease in the rain amount and an increase in the dew amount after 2010. For sake of comparison in the whole time period, the data (Fig. 7b) can be fitted to a mean constant value

$a(t)=a_{0}$

The values of $a_{0}$ according to the three $N$ scenarios are summarized in Table 3. Taking into account all stations, the parameter $a_{0}$ shows a large variability: $\overline{a_{0}}=0.4 \pm 0.8(N=0)$, $\overline{a_{0}}=0.3 \pm 0.6(N=1)$ and $\overline{a_{0}}=0.15 \pm 0.27(N=3)$. This variability is due to the small number and erratic character of the precipitations in arid areas. When the very small quantities of rain at these sites (Namib Desert: Oranjemund, Luderitz, Swakopmund and Walvis Bay) are removed, the variability of values becomes much smaller $\left(\overline{a_{0}}=0.022 \pm 0.008(N=0)\right.$, $\overline{a_{0}}=0.020 \pm 0.009(N=1)$ and $\left.\overline{a_{0}}=0.017 \pm 0.011(N=3)\right)$.

The parameter $\overline{a_{0}}$ is mapped by the Kriging method in Fig. 8 . One can clearly observe the increasing importance of dew in
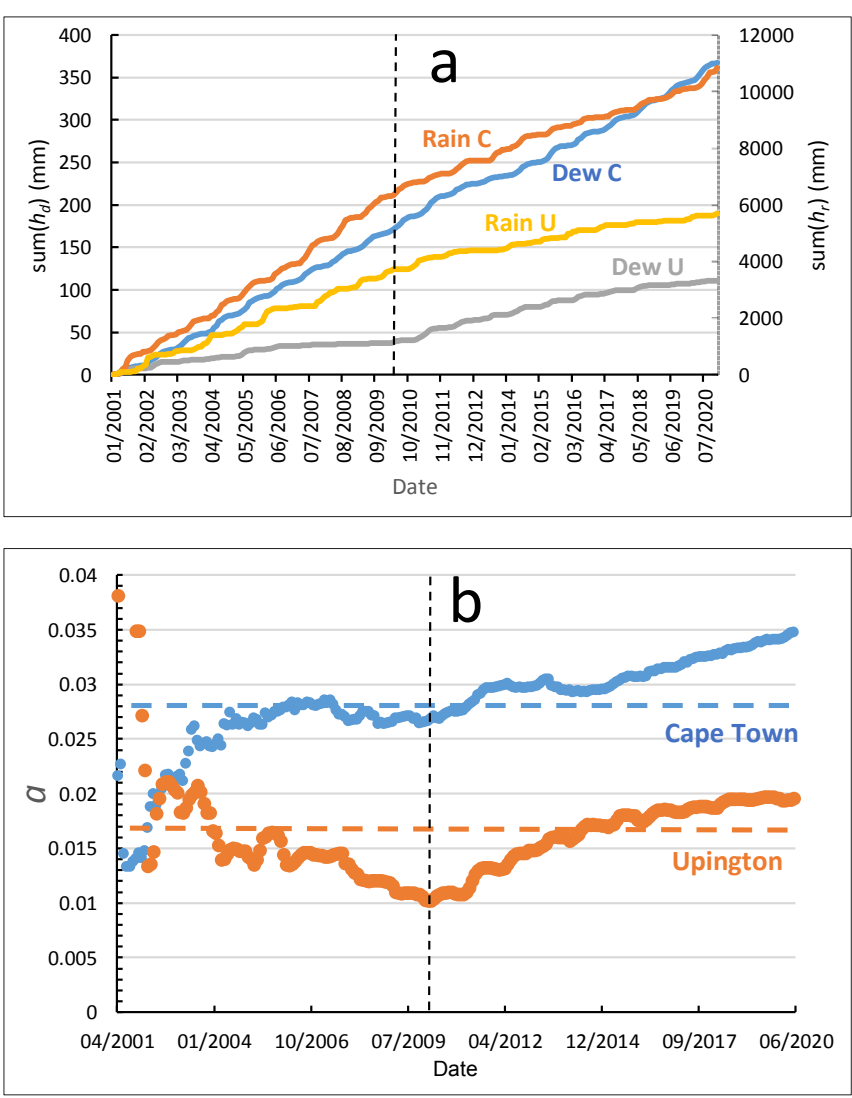

Fig. 7. Two typical evolutions (Upington $U$ and Cape Town $\mathrm{C}$ sites) of dew and rain summed yields in the studied period (20012020). The vertical dotted line corresponds to year 2010 where rainfalls begin to significantly decrease. (a) $\operatorname{sum}\left(h_{d}\right)$ and $\operatorname{sum}\left(h_{r}\right)$ with $N=0$ missing data scenario (see text and Table 1). (b) Ratio $a(t)=\left[\operatorname{sum}\left(h_{d}\right)\right]_{t} /\left[\operatorname{sum}\left(h_{r}\right)\right]_{t}$. The horizontal straight lines are fits to $a(t)=a_{0}=$ constant

Table 3. Ratio dew/rain summed amplitudes $a_{0}$ (Eq. 9) according to different $N$ assumptions for the missing data (see text and Table 1).

\begin{tabular}{|l|c|c|c|}
\hline Site & $a_{0}(N=0)$ & $a_{0}(N=1)$ & $a_{0}(N=3)$ \\
\hline Swakopmund & 2.384 & 1.793 & 0.792 \\
\hline Walvis Bay & 2.444 & 1.841 & 0.832 \\
\hline Luderitz & 1.154 & 0.940 & 0.569 \\
\hline Ondangwa & 0.023 & 0.016 & 0.006 \\
\hline Oranjemund & 0.858 & 0.651 & 0.282 \\
\hline Eros & 0.014 & 0.011 & 0.006 \\
\hline Keetmanshoop & 0.020 & 0.014 & 0.006 \\
\hline Cape Town & 0.028 & 0.028 & 0.028 \\
\hline Upington & 0.017 & 0.015 & 0.012 \\
\hline Shakawe & 0.011 & 0.011 & 0.011 \\
\hline George & 0.031 & 0.027 & 0.024 \\
\hline Maun & 0.007 & 0.007 & 0.007 \\
\hline Mahikeng & 0.013 & 0.011 & 0.007 \\
\hline Port Elizabeth & 0.026 & 0.026 & 0.026 \\
\hline Gaborone & 0.028 & 0.028 & 0.028 \\
\hline Bram Fischer & 0.034 & 0.032 & 0.029 \\
\hline Francistown & 0.018 & 0.018 & 0.018 \\
\hline Wonderboom & 0.034 & 0.034 & 0.034 \\
\hline
\end{tabular}


the total precipitations along the Namibian coast and more generally the dependence of $a$ on longitude. It corroborates the fact that the distance from the ocean, which controls the atmosphere RH (see Fig. 2), is the important parameter for the formation of dew. Toward the west, dew increases (Fig. 2) and rain decreases (Fig. 4), leading to an increase in $a$.

The variation of the ratio $a$ between 2020 and 2011 is reported in Fig. 9. One verifies the general increase of the contribution of dew with respect to rain, especially towards west.

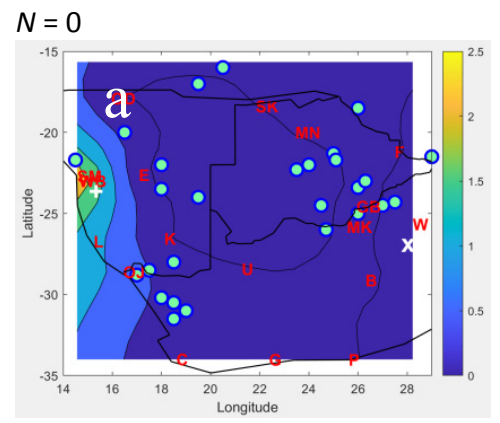

\subsection{Time period of events}

Because the frequency or time period between rain events is also an important parameter, which in itself can control the biocrust growth, we investigate below this parameter for rain only, dew only and dew plus rain. For that purpose, one considers the histogram of rain, dew and rain plus dew events (Fig. 10) where two important parameters can be extracted, the mean time period between events, $\theta_{0}$ (in days) and the maximum time period, $\theta_{M}$ (in days).

Fig. 8. Map of ratio $a_{0}$ corresponding to the average of $a=\operatorname{sum}(\mathrm{dew}) / \mathrm{sum}($ rain) (Eqs. 8, 9) for the period 2001-2020 and three scenarios for missing $N$ data (see text and Table 1). Letters: meteo sites; circles: biocrust sites according to Chen et al. (2020); right cross: Gobabeb site studied by Henschel et al. (2007) and Soderberg (2010); inclined cross: Potchefstroom site studied by Baier (1966).
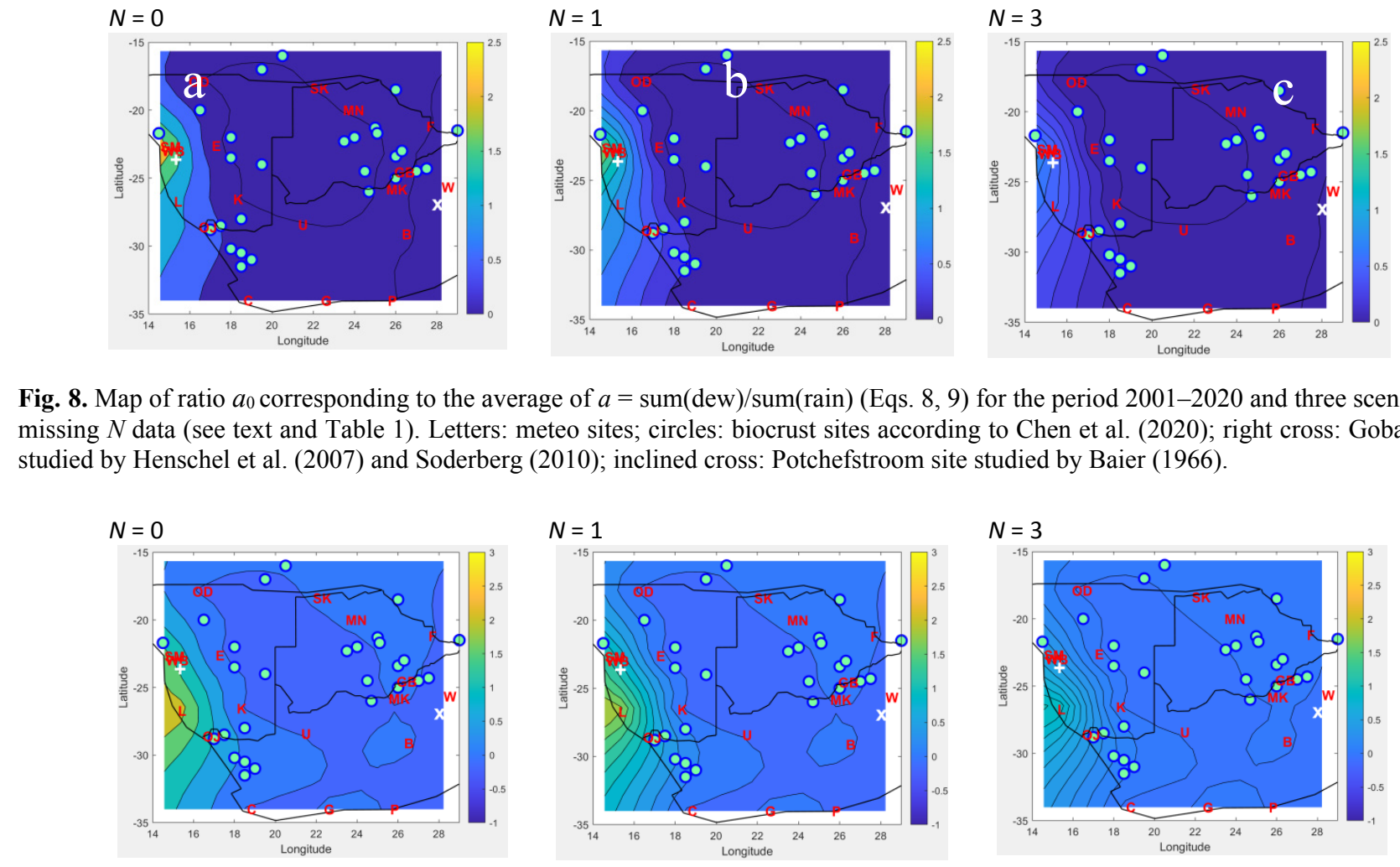

Fig. 9. Variation between 2020 and 2011 of the ratio $a_{0}=\operatorname{sum}(\mathrm{dew}) / \mathrm{sum}($ rain), corresponding to 3 scenarios for missing $N$ data (see text and Table 1). Letters: meteo sites; circles: biocrust sites according to Chen et al. (2020); right cross: Gobabeb site studied by Henschel et al. (2007) and Soderberg (2010); inclined cross: Potchefstroom site studied by Baier (1966).

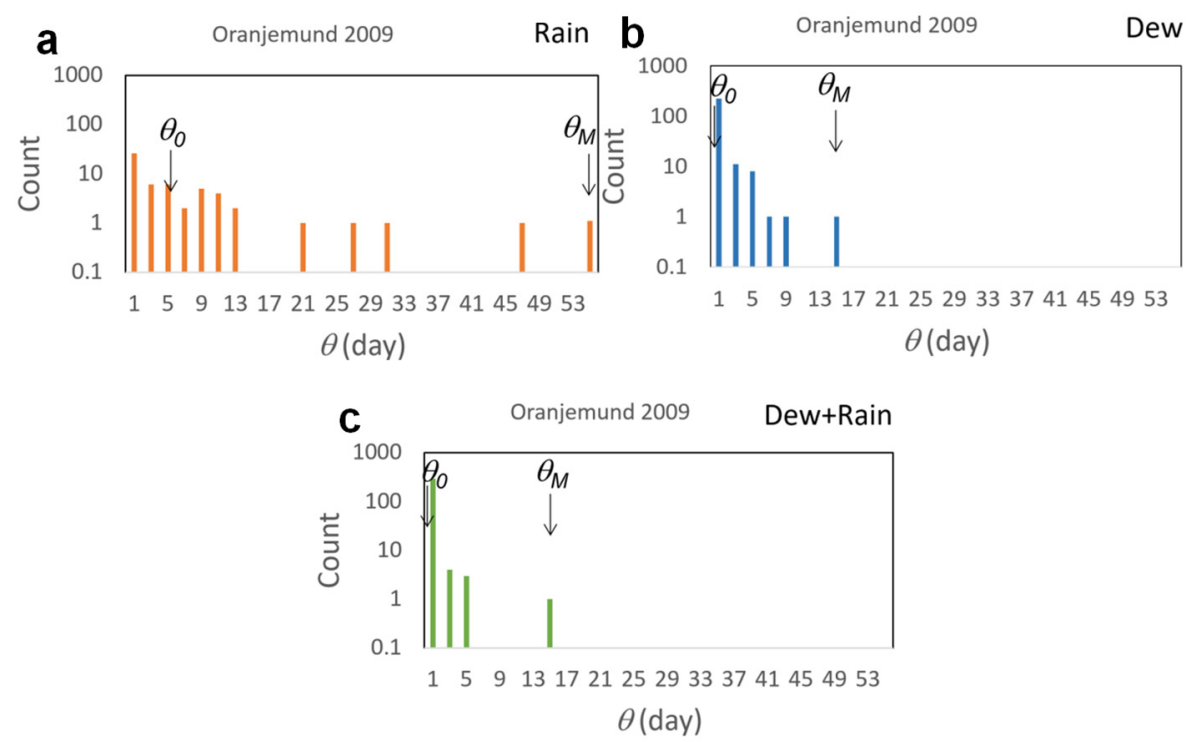

Fig. 10. Typical histograms of time period $\theta$ (day) beetween (a) rain events, (b) dew events (c) rain and dew events. $\theta_{0}$ is the mean time and $\theta_{M}$ is the maximum time. Note that some dew or rain events can disappear in the histogram dew + rain because dew or rain events occur during the dew or rain time periods. 
The evolution of $\theta_{0}$ and $\theta_{M}$ can be then considered (Fig. SM2) and maps of mean values can be drawn for the considered period (Fig. 11), with the difference between 2011 and 2020 values (Fig. 12). Some curves are interrupted due to the lack of data.

One first notes from Figs. 10 and SM2 (in Supplementary Materials) that the number of events is larger for dew than for rain. In addition, the timescale for mean and maximum time period between events is much larger for rain than for dew, a difference
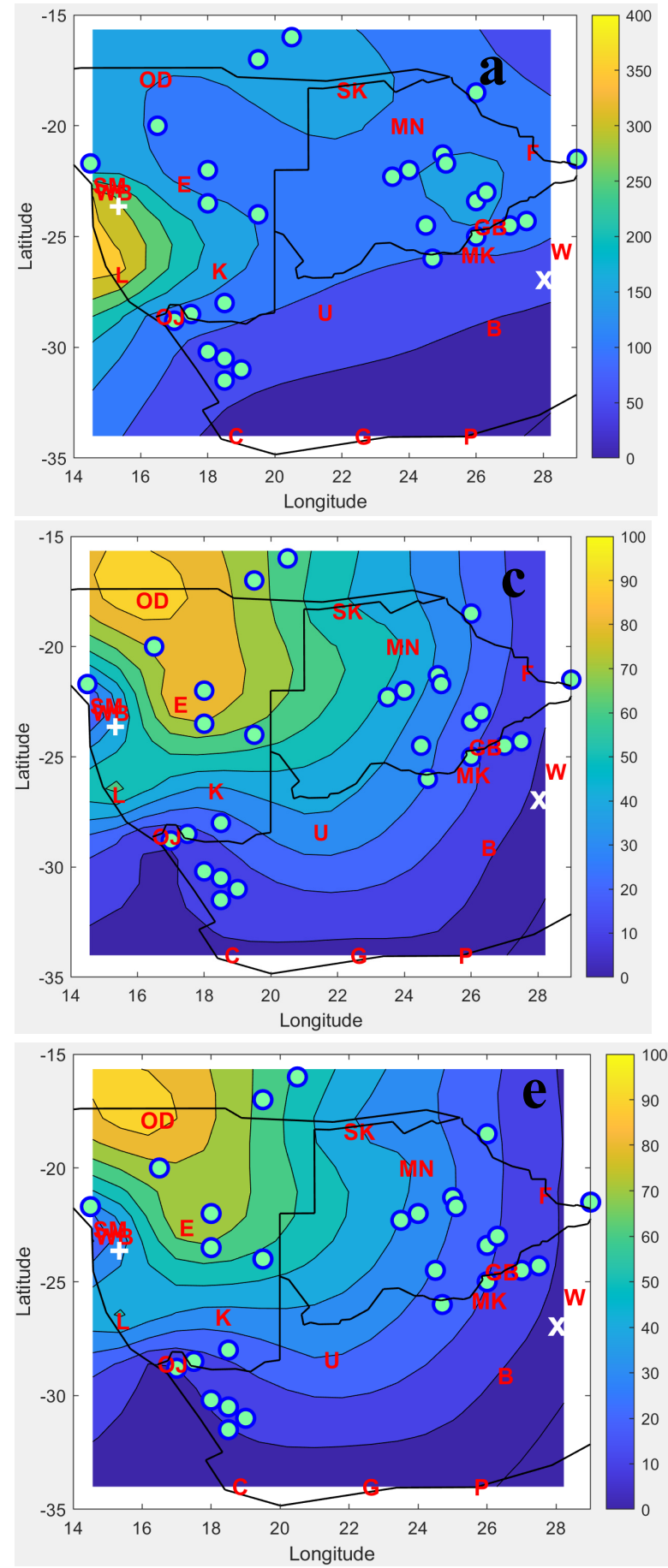

which can reach two orders of magnitudes. It results from the above observations that the dew events will determine the behavior of the dew + rain time period (see Fig. SM2, Figs. 11-12).

When comparing the maps of dew and rain mean annual times (Fig. 11) and dew and rain amplitudes (Figs. 2 and 4), one observes a strong correlation between the zones of large times and low yield, and short times and high yield. This simply means that large water yields correspond to frequent dew or rain events.
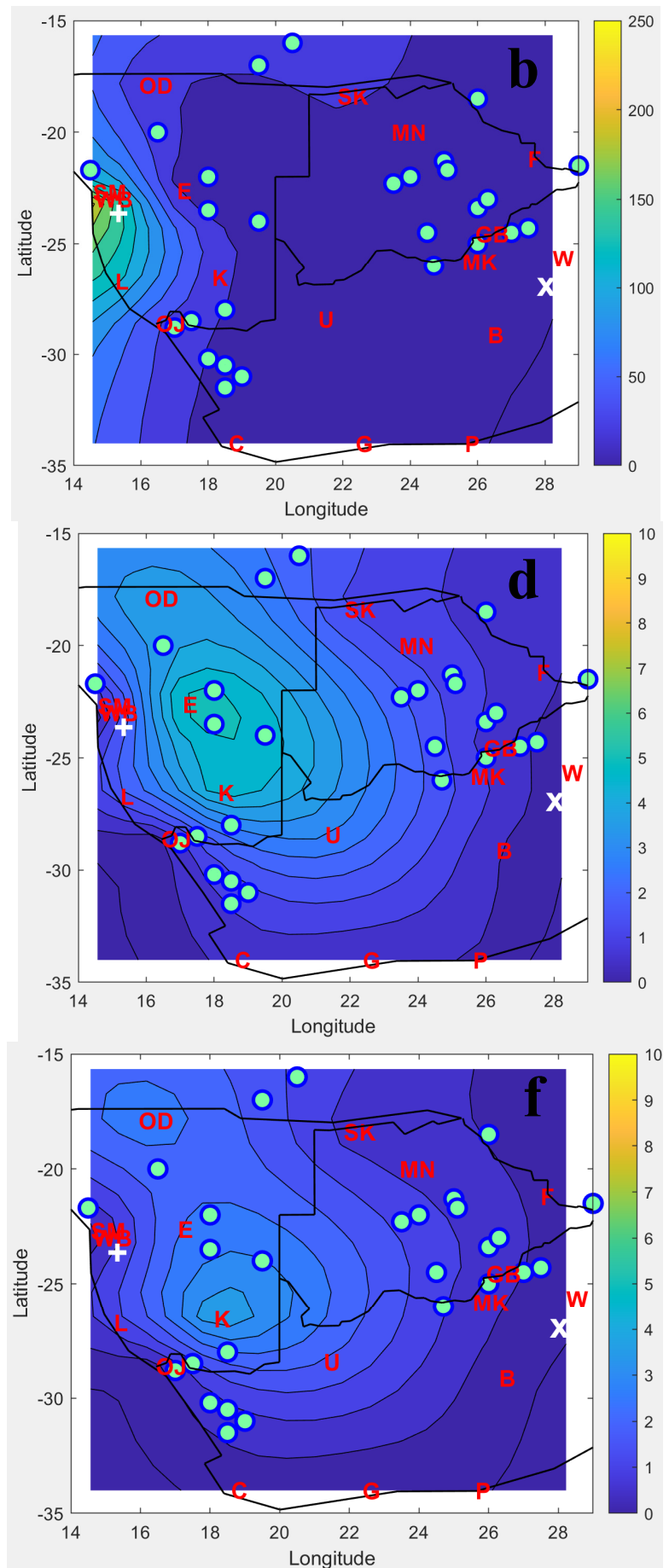

Fig. 11. Annual mean in the period 2001-2020 of the maximum time $\theta_{M}$ (day) (left column) and mean time $\theta_{0}$ (day) (right column). (a), (b): Rain; (c), (d): Dew; (e), (f): Rain+dew. Red letters: Measurement sites (see Table 1); circles: biocrust sites according to Chen et al. (2020); right cross: Gobabeb site studied by Henschel et al. (2007) and Soderberg (2010); inclined cross: Potchefstroom site studied by Baier (1966). 

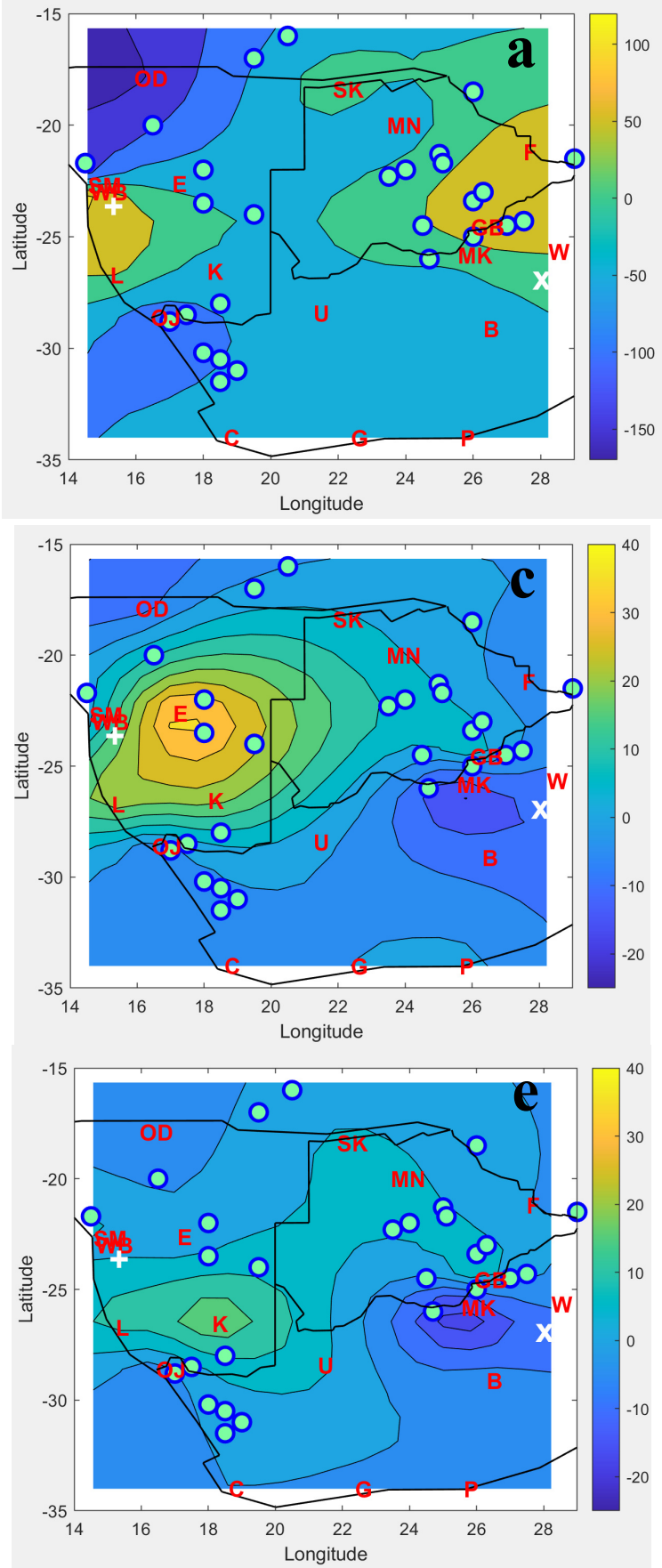
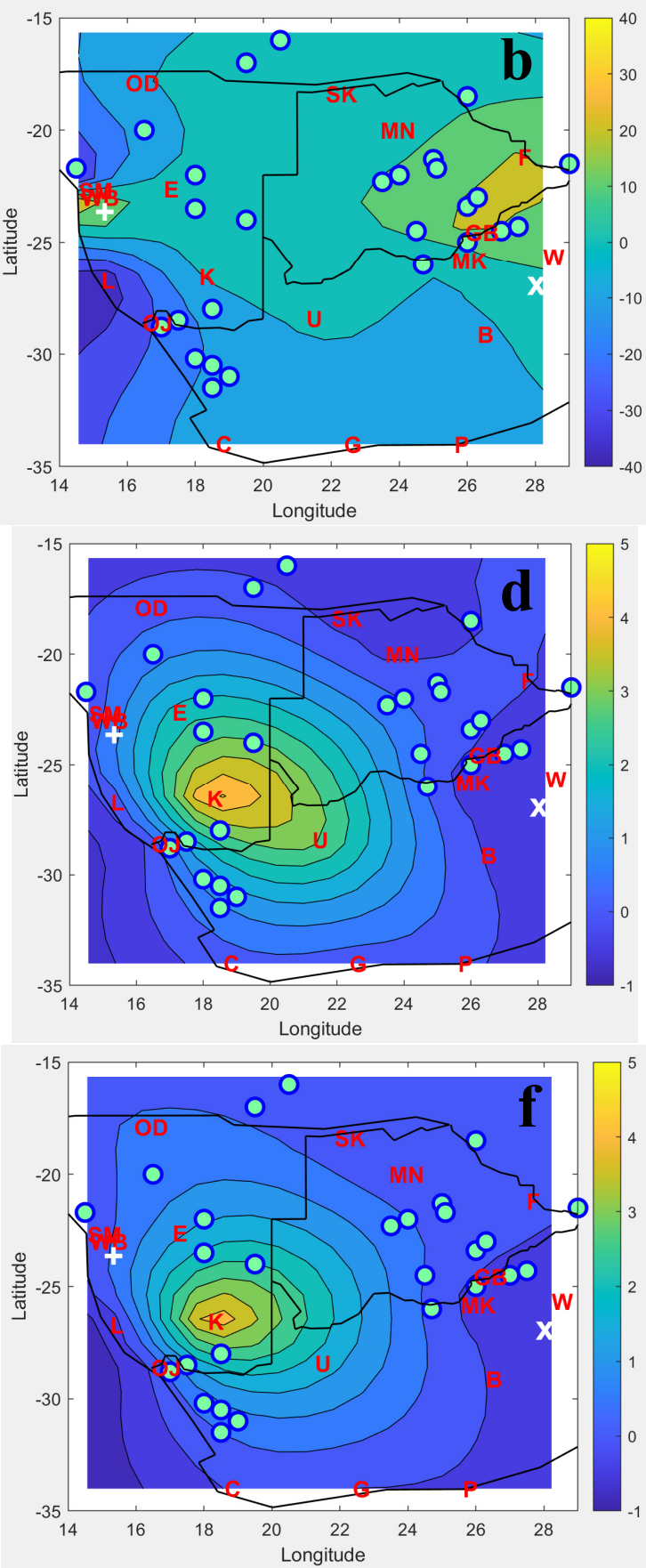

Fig. 12. Difference between 2020 and 2011 of the maximum time $\theta_{M}$ (left column, day) and mean time $\theta_{0}$ (right column, day). (a), (b): Rain; (c), (d): Dew; (e), (f): Rain+dew. Red letters: Measurement sites (see Table 1); circles: biocrust sites from Chen et al. (2020); right cross: Gobabeb site studied by Henschel et al. (2007) and Soderberg (2010); inclined cross: Potchefstroom site studied by Baier (1966).

The evolution of the mean and maximum time period between 2001 and 2020 (Fig. SM2) show that mean and maximum time periods evolve about the same way. The times keep nearly constant over the whole period for dew, noting some decrease after 2010. Dew frequency is well correlated with the dew yield amplitude, which remains constant or weakly increases in the same period (Fig. SM1 in Supplementary Materials). In contrast, for rain, while the times keep constant between 2001 and 2010, the times increase after 2010. This evolution corresponds well with the decrease of rain amplitude (Fig. SM1).

The maps of evolution for the period 2011-2020 concerning the differences in rain, dew and rain + dew times are reported in Fig. 12. The evolution of mean and maximum times are qualita- tively similar to the evolution of the rain and dew amplitudes (Figs. 3 and 5). The inverse evolution of rain + dew times rather follows the dew evolution, as expected from the fact noted above that the dew events mostly determine the behavior of the dew + rain times.

\section{DISCUSSION AND RELATION WITH BIOCRUST 4.1 Dew height dependence}

Biocrust forms at the ground level while the calculation of Section 2.1 deals with a $30^{\circ}$ tilted condenser at $1 \mathrm{~m}$ off the ground. Dew condensation can vary for three reasons. (i) $\mathrm{RH}$ can be height dependent. This is the case if wind speed is near 
zero and soil is wet, for instance after a rain event. (ii) Air flow depends on height, and then, the heat and mass exchange with the surrounding air. The variation of air flow velocity is known to follow a $\log$ dependence above a roughness length $z_{c}$ (see Section 2.3) where air flow velocity is zero. In addition to the forced air flow induced by wind, there exists a natural convection induced by the substrate temperature colder than ambient air, with typical velocity $0.6 \mathrm{~m} \mathrm{~s}^{-1}$ (Beysens et al., 2005; Clus et al., 2009). The log dependence of the windspeed and the presence of natural convection make the heat exchange coefficient and then the mass diffusion coefficient, which determines the condensation yield, depend weakly of windspeed for values below $\sim 1 \mathrm{~m} \mathrm{~s}^{-1}$ (measured at the standard height of $10 \mathrm{~m}$ ). It results a weak dependence of condensation with height for such windspeeds, making the calculation of Section 2.1 valid at the ground level.

For larger windspeeds, the heat exchange coefficients will be larger, decreasing the dew yield. The latter will be then larger at the ground level and the calculation of Section 2.1 will be a conservative value.

\subsection{Comparison with direct dew yield measurements}

The calculated dew yields can be compared with previous works available in the literature. Baier (1966) reported dew and rainfall measurements from a weather station set at Potchefstroom (inclined cross in Fig. 2), located in the vast interior plateau of South Africa (26 $44^{\prime} \mathrm{S}, 2^{\circ} 05^{\prime} \mathrm{E}, 1352 \mathrm{~m}$ asl), about $160 \mathrm{~km}$ from the Wonderboom site. During the period 1957-1958, the annual percentage of dew days was $45.7 \%$ (Wonderboom: $65.5 \%$ ) with a mean annual dew amount of $12.6 \mathrm{~mm}$ (Wonderboom: $19.9 \mathrm{~mm}$ ). The values in Wonderboom are slightly larger, but the measurement time was earlier and we will see in the next Section that the general tendency is a positive dew yield evolution.

Dew collection were also carried out in 2006 by Henschel et al. (2007) at Gobabeb (Namib Desert, 2333.704 S, $15^{\circ} 02.466 \mathrm{E}$, right cross in Fig. 2) in Namibia's Central Namib Desert, situated about $84 \mathrm{~km}$ from Walvis Bay and $110 \mathrm{~km}$ from Shakopmund. The site elevation is $406 \mathrm{~m}$. Only a few data were collected on a specially-designed $1 \mathrm{~m}^{2}$ passive dew collector. In July 2006, 3.3 $\mathrm{mm}$ of dew water was collected (12 dew days), $1.2 \mathrm{~mm}$ in August (10 dew days), and $1.5 \mathrm{~mm}$ in September (10 dew days). Meteo data at Walvis Bay and Shakopmund are, however, available only between 2010 and 2020. In these cities, the calculated annual mean in July, August and September are nearly the same: $2.6 \mathrm{~mm}$ (July), $2.2 \mathrm{~mm}$ (August) and $2.2 \mathrm{~mm}$ (September) $(N=$ $0), 1.2 \mathrm{~mm}, 1.8 \mathrm{~mm}$ and $1.7 \mathrm{~mm}(N=1)$ and $0.7 \mathrm{~mm}, 0.9 \mathrm{~mm}$ and $0.9 \mathrm{~mm}(N=3)$. Although not determined at the same dates, these values compare relatively well with the above measured values of $3.3 \mathrm{~mm}$ (July), 1.2 (August) and $1.5 \mathrm{~mm}$ (September).

Between July 2008 and June 2009, Soderberg (2010) measured a greater amount of dew at Gobabeb, with 143 yearly dew events. The corresponding volume was $12.3 \mathrm{~mm}$, which compares relatively well with the Walvis Bay and Shakopmund data for the same year: $21 \mathrm{~mm}(N=0), 15.8 \mathrm{~mm}(N=1), 7 \mathrm{~mm}$ $(N=3)$.

\subsection{Variation in rain precipitation}

As mentioned in Section 3.3, we observed a decrease of precipitation from west to east. All sites present a negative variation in rain precipitation during 2001 to 2020. In particular, the decrease in precipitation is quite noticeable from 2010. In Namibia Lu et al. (2016) also observed a tendency to a diminution of rainfall precipitations. On the Ghaap plateau in west center of South Africa, oscillations of rain precipitations have been already noted by Tfwala et al. (2018) by analyzing interannual rainfall variability on the Ghaap plateau. The cycles last about 18-22 years in Postmarburg and between 12 and 16 years in Douglas. Another analysis of rainfall in South Africa by Zvarevashe at al. (2018) also concluded to quasi-decadal oscillations. The question whether the decrease we observed since 2010 is related to these oscillations or to the global climate change remains thus open.

\subsection{Water availability and biocrust distribution}

As outlined in the Introduction, the amount of rain and dew are considered as the main factors which influence the growth of biocrust (see e.g. Kidron and Kronenfeld, 2020; Li et al., 2021a, b; Ouyang et al.; 2017; Pan et al., 2010; Zhuang and Zhao, 2017). However, the frequency of rain events (longest period of drought) is the main factor according to Büdel et al. (2009). Although there are no studies concerning the effect of frequency of dew events, one can reasonably assume that this parameter also matters.

Frequency of events and their amplitude are strongly correlated (see Section 3.5), the regions of large dew or rain amplitudes corresponding to the regions of small dew or rain time periods. Both criteria (amplitude, frequency) should thus correspond in the studied regions to the same characteristics favoring biocrust growth.

The evolution between 2001 and 2020 is seen to exhibit two regimes, one from 2001 to 2010, where all parameters (dew and rain amplitude, dew and rain frequency) keep nearly constant. The second regime, from 2010 to 2020 , corresponds to a neat decrease of rain amplitude and frequency of events, while dew amplitude and frequency either keeps constant or slightly increase. As far as rain is concerned, it should result in a decrease of biocrust growth. However, dew yield is nearly constant or increases after 2010. We are not aware of drastic changes in the distribution of biomass of biocrusts during the 2001-2020 period. This may be attributed to the increase of dew amplitude and frequency, which should act to compensate for the decrease in rain precipitation.

\section{CONCLUSION AND TRENDS FOR THE FUTURE}

The determination of dew yield using a physical model and rainfall data from 18 meteorological stations in Namibia, Botswana and South Africa in the period 2001-2020 allow clear tendencies to be evaluated. Dew decreases from the East, South, West coasts following the decrease in RH decrease, and rainfalls diminish toward the West and North. A noticeable decrease in rain precipitations after 2010 and a corresponding rise in dew yield are noted. It results in a steady increase of dew contribution with respect to rain after 2010. In addition, a clear increase in dew for three days in average after rainfall is observed in the arid regions where the humidity is low. These results are corroborated with the frequency of dew and rain events, which are closely correlated with dew and rain yields.

The effect on biocrust is to show zones with less rain but with increasing dew water. As far as rain is concerned, one therefore should expect a decrease of biocrust growth. However, dew yield is nearly constant or even increases after 2010, which could possibly compensate the rain decrease as we are not aware of drastic changes in the distribution of biomass of biocrusts during the 2001-2020 period. 
The observed evolution, studied from 2001, exhibits a change after 2010. The question whether this decrease is related to oscillations or to a general tendency due to the global climate change remains open. A more precise scenario will need the use of climate change models as was done by Tomaszkiewicz et al. (2016). We plan such a study in a near future.

Acknowledgements. We gratefully G. Kidron for his valuable remarks and G.A. Faggianelli for his work in data extraction from the Weather Undergound database.

\section{REFERENCES}

Aguirre-Gutiérrez, C.A., Holwerda, F., Goldsmithc, G.R., Delgado, J., Yepez, E., Carbajal, N., Escoto-Rodríguez, M., Arredondo, J.T., 2019. The importance of dew in the water balance of a continental semiarid grassland. J. Arid Environ., $168,26-35$.

Amani, A., Lebel, T., 1997. Lagrangian Kriging for the estimation of Sahelian rainfall at small time steps. J. Hydrol., 192, 125-157.

Baier, W., 1966. Studies on dew formation under semi-arid conditions. Agric. Meteorol., 3, 103-112.

Bargaoui, Z., Chebbi, A., 2009. Comparison of two Kriging interpolation methods applied to spatiotemporal rainfall. J. Hydrol., 365, 56-73.

Belkiri, L., Tiri, A., Mouni, L., 2020. Spatial distribution of the groundwater quality using Kriging and Co-Kriging interpolations. Groundw. Sustainable Dev., 11, 100473.

Beysens, D., 2016. Estimating dew yield worldwide from a few meteo data. Atmos. Res., 167, 146-155.

Beysens, D., Muselli, M., Nikolayev, V., Narhe, R., Milimouk, I., 2005. Measurement and modelling of dew in island, coastal and alpine areas. Atmos. Res., 73, 1-22.

Büdel, B., Darienko, T., Deutschewitz, K., Dojani, S., Friedl, S., Mohr, K.I., Salisch, M., Reisser, W., Weber, B., 2009. Southern African biological soil crusts are ubiquitous and highly diverse in drylands, being restricted by rainfall frequency. Microb. Ecol., 57, 229-247.

Cano-Díaz, C., Mateoa, P., Muñoz-Martína, M.A., Maestre, F.T., 2018. Diversity of biocrust-forming cyanobacteria in a semiarid gypsiferous site from Central Spain. J. Arid Environ., 151, 83-89.

Chen, N., Yu, K., Jia, R., Teng, J., Zhao, C., 2020. Biocrust as one of multiple stable states in global drylands. Sci. Adv., 6, eaay3763.

Clus, O., Ouazzani, J., Muselli, M., Nikolayev, V.S., Sharan, G. Beysens, D., 2009. Comparison of various radiation-cooled dew condensers using computational fluid dynamics. Desalination, 249, 707-712.

Goovaerts, P., 1997. Geostatistics for Natural Resources Evaluation. Oxford University Press, New York, 500 p.

Henschel, J., Siteketa, V., Berkowicz, S.M., Beysens, D., Milimouk-Melnytchouk, I., Muselli, M., Heusinkveld, B.G., Jacobs, A.F.G., 2007. Dew occurrence and collection in Gobabeb, Central Namib Desert. In: Proc. 4th Conf. on Fog, Fog Collect. and Dew (La Serena, Chile, 23-27 July 2007), p. 251.

Infoclimat database, 2021. https://www.infoclimat.fr

Jacobs, A.F.G., Heusinkveld, B.G., Berkowicz, S.M., 2002. A simple model for potential dewfall in an arid region. Atmos. Res., 64, 285-295.

Jones, A., Breuning-Madsen, H., Brossard, M., Dampha, A., Deckers, J., Dewitte, O., Gallali, T., Hallett, S., Jones, R., Kilasara, M., Le Roux, P., Micheli, E., Montanarella, L., Spaargaren, O., Thiombiano, L., Van Ranst, E., Yemefack,
M., Zougmoré R., (eds.), 2013. Soil Atlas of Africa. European Commission, Publications Office of the European Union, Luxembourg, $176 \mathrm{p}$.

Kidron, G.J., 2019. The enigmatic absence of cyanobacterial biocrust from the Namib fog belt: Do dew and fog hold the key? Flora, 257, 151416.

Kidron, G.J., Tal, S.Y., 2012. The effect of biocrust on evaporation from sand dunes in the Negev Desert. Geoderma, 179-180, 104-112.

Kidron, G.J., Kronenfeld, R., 2020. Assessing the likelihood of the soil surface to condense vapour: The Negev experience. Ecohydrol., 13, e2200.

Lepioufle, J.M., Leblois, E., Creutin, J.D., 2012. Variography of rainfall accumulation in presence of advection. J. Hydrol., 464-465, 494-504.

Li, S., Bowker, M.A., Xiao, B., 2021a. Biocrust enhance nonrainfall water deposition and alter its distribution in dryland soils. J. Hydrol., 595, 126050.

Li, S., Xiao, B., Kidron, G.J., 2021b. Moss-dominated biocrust enhance water vapor sorption capacity of surface soil and increase non-rainfall water deposition in drylands. Geoderma 388, 114930.

Lima, C.H.R., Kwon, H.H., Kim, Y.T., 2021. A Bayesian Kriging model applied for spatial downscaling of daily rainfall from GCMs. J. Hydrol., 597, 126095.

Lu, X., Wang, L., Pan, M., Kaseke, K.F., Li, B., 2016. A multiscale analysis of Namibian rainfall over the recent decade comparing TMPA satellite estimates and ground observations. J. Hydrol. Reg. Stud., 8, 59-68.

Martinez, W.A., Melo, C.E., Melo, O.O., 2017. Median Polish Kriging for space-time analysis of precipitation. Spat. Stat., $19,1-20$.

Muselli, M., Clus, O., Ortega, P., Milimouk, I., Beysens, D., 2020. Physical, chemical and biological characteristics of dew and rain water during the dry oceans on of tropical islands. Atmos., 12, 69.

New, M., Hulme, M., Jones, P., 2000. Representing twentiethcentury space-time climate variability. Part II: Development of 1901-96 monthly grids of terrestrial surface climate. J. Climatol., 12, 829-856.

NOAA's national weather service glossary, 2021. Available online: https://www.forecast.weather.gov (accessed on 13 February 2021).

Ouyang, H., Lan, S., Yang, H., Hu, C., 2017. Mechanism of biocrust boosting and utilizing non-rainfall water in Hobq Desert of China. Appl. Soil Ecol., 120, 70-80.

Pal Arya, S., 1988. Introduction to Micrometeorology. Acad. Press, San Diego, 307 p.

Pan, Y., Wan, X., Zhang, Y., 2010. Dew formation characteristics in a revegetation-stabilized desert ecosystem in Shapotou area, northern China. J. Hydrol., 387, 265-272.

Pue, J.D., Botula, Y.D., Nguyen, P.M., Meirvenne, M.V., Cornelis, W.M., 2021. Introducing a Kriging-based Gaussian Process approach in pedotransfer functions: Evaluation for the prediction of soil water retention with temperate and tropical datasets. J. Hydrol., 597, 125770.

Raggio, J., Green, A., Pintado, A., Sancho, L.G., Büdel, B., 2021. Functional performance of biocrust across Europe and its implications for drylands. J. Arid Environ., 186, 104402.

Rahmawati, N., 2020. Space-time variogram for daily rainfall estimates using rain gauges and satellite data in mountainous tropical Island of Bali, Indonesia (Preliminary Study). J. Hydrol., 590, 125177.

Railsback, L.B., Kraft, S., Liang, F., Brook, G.A., Marais, E., Cheng, H., Edwards, R.L., 2019. Control of insolation on 
stalagmite growth, rainfall, and migration of the tropical rain belt in northern Namibia over the last $100 \mathrm{kyr}$, as suggested by a rare MIS 5b-5c stalagmite from Dante Cave. Palaeogeogr., Palaeoclimatol., Palaeoecol., 535, 109348.

Soderberg, K.S., 2010. The role of fog in the ecohydrology and biogeochemistry of the Namib Desert. MSc. Thesis, University of Cape Town, Department of Environmental Sciences, University of Virginia.

Tomaszkiewicz, M., Najm, A., Beysens, D., Alameddine, I., Zeid, E.B., El-Fadel, M., 2016. Projected climate change impacts upon dew yield in the Mediterranean basin. Sci. Total. Environ., 566-567, 1339-1348.

Trosseille, J., Mongruel, A., Royon, L., Beysens, D., 2022. Effective surface emissivity during dew water condensation. International Journal of Heat and Mass Transfer, 183, 122078.

Tfwala, C.M., Van Rensburga, L.D., Schallb, R., Dlamini, P., 2018. Drought dynamics and interannual rainfall variability on the Ghaap plateau, South Africa, 1918-2014. Phys. Chem. Earth, 107, 1-7.
Van de Beek, C.Z., Leijnse, H., Torfs, P.J.J.F., Uijlenhoet, R., 2012. Seasonal semi-variance of Dutch rainfall at hourly to daily scales. Adv. Water Resour., 45, 76-85.

Weather Underground database, 2021. https://www.wunder ground.com

Yao, X., Xia, B., Kidron, G.J., Hu, K., 2019. Respiration rate of moss-dominated biocrust and their relationships with temperature and moisture in a semiarid ecosystem. Catena, 183, 104195.

Zhuang, Y., Zhao, W., 2017. Dew formation and its variation in Haloxylon ammodendron plantations at the edge of a desert oasis, northwestern China. Agric. For. Meteorol., 247, 541-550.

Zvarevashe, W., Krishnannair, S., Sivakumar, V., 2018. Analysis of Austral Summer and Winter Rainfall Variability in South Africa Using Ensemble Empirical Mode Decomposition. IFAC paperOnline, 51-5, 132-137.

Received 20 June 2021 Accepted 1 October 2021 
Mapping past, present and future dew and rain water resources for biocrust evolution in southern Africa

\section{Appendix 1 - Dew yield calculation}

We give below in Table SM1 an example of determination of dew yield from Section 2.1. The model (Eq. 2) is applied to one night (March 21-22, 2010) in Cape Town (South Africa). Considering the sky cloud cover $(N$, oktas $)$, the air $\left(T_{a},{ }^{\circ} \mathrm{C}\right)$ and dew $\left(T_{d},{ }^{\circ} \mathrm{C}\right)$ temperatures, the relative humidity $(\mathrm{RH}, \%)$ and the wind-speed $\left(V, \mathrm{~m} \mathrm{~s}^{-1}\right)$ at 10 meters of the ground, recorded every $\Delta t=1 \mathrm{~h}$., we compute an hourly yield $h_{i}(\mathrm{~mm})$ corresponding to evaporation $\left(h_{i}<0\right)$ or condensation $\left(h_{i}>0\right)$ events. By discarding evaporation $\left(h_{i}<0\right)$ and rain events, the cumulative dew yield $h$ for each night is computed. For the studied night, $h=0.185 \mathrm{~mm}$.

Table SM1. Exemple of calculation of dew yields from meteorological data.

\begin{tabular}{|c|c|c|c|c|c|c|c|c|c|c|}
\hline $\begin{array}{c}\text { Date } \\
(\mathrm{dd} / \mathrm{mm} / \mathbf{a a a a})\end{array}$ & $\begin{array}{c}\begin{array}{c}\text { Hour } \\
\text { (hh:mm) }\end{array} \\
\end{array}$ & $\begin{array}{c}N \\
\text { (oktas) } \\
\end{array}$ & $\begin{array}{c}V \\
(\mathrm{~m} / \mathrm{s}) \\
\end{array}$ & $\begin{array}{c}T_{a} \\
\left({ }^{\circ} \mathrm{C}\right) \\
\end{array}$ & $\begin{array}{l}\text { RH } \\
(\%) \\
\end{array}$ & $\begin{array}{c}T_{d} \\
\left({ }^{\circ} \mathrm{C}\right) \\
\end{array}$ & $\begin{array}{c}T_{d}-T_{a} \\
\left({ }^{\circ} \mathrm{C}\right) \\
\end{array}$ & $\begin{array}{c}\begin{array}{c}h_{i} \\
(\mathrm{~mm})\end{array} \\
\end{array}$ & $\begin{array}{l}h_{i}>0 \\
(\mathbf{m m})\end{array}$ & $\begin{array}{c}\operatorname{sum}\left(h_{i}\right) \\
(\mathrm{mm})\end{array}$ \\
\hline $21 / 03 / 2010$ & $12: 00$ & 5 & 6.1 & 22 & 69 & 16 & -6 & -0.030 & 0.000 & 0.000 \\
\hline $21 / 03 / 2010$ & 13:00 & 5 & 7.2 & 23 & 65 & 16 & -7 & -0.035 & 0.000 & 0.000 \\
\hline $21 / 03 / 2010$ & $14: 00$ & 3 & 7.8 & 22 & 69 & 16 & -6 & -0.030 & 0.000 & 0.000 \\
\hline $21 / 03 / 2010$ & $15: 00$ & 1 & 7.8 & 22 & 69 & 16 & -6 & -0.030 & 0.000 & 0.000 \\
\hline $21 / 03 / 2010$ & $16: 00$ & 1 & 6.1 & 22 & 69 & 16 & -6 & -0.030 & 0.000 & 0.000 \\
\hline $21 / 03 / 2010$ & $17: 00$ & 1 & 5.6 & 21 & 68 & 15 & -6 & -0.030 & 0.000 & 0.000 \\
\hline $21 / 03 / 2010$ & 18:00 & 1 & 4.7 & 19 & 83 & 16 & -3 & -0.015 & 0.000 & 0.000 \\
\hline $21 / 03 / 2010$ & 19:00 & 0 & 3.1 & 18 & 88 & 16 & -2 & 0.014 & 0.014 & 0.014 \\
\hline $21 / 03 / 2010$ & $20: 00$ & 0 & 0.6 & 18 & 88 & 16 & -2 & 0.014 & 0.014 & 0.027 \\
\hline $21 / 03 / 2010$ & 21:00 & 0 & 1.9 & 15 & 94 & 14 & -1 & 0.019 & 0.019 & 0.046 \\
\hline $21 / 03 / 2010$ & $22: 00$ & 0 & 3.1 & 14 & 100 & 14 & 0 & 0.024 & 0.024 & 0.070 \\
\hline $21 / 03 / 2010$ & 23:00 & 0 & 3.1 & 17 & 88 & 15 & -2 & 0.014 & 0.014 & 0.084 \\
\hline $22 / 03 / 2010$ & 00:00 & 0 & 3.1 & 17 & 88 & 15 & -2 & 0.014 & 0.014 & 0.098 \\
\hline $22 / 03 / 2010$ & 01:00 & 0 & 3.1 & 17 & 94 & 16 & -1 & 0.019 & 0.019 & 0.117 \\
\hline $22 / 03 / 2010$ & 02:00 & 0 & 4.2 & 17 & 94 & 16 & -1 & 0.012 & 0.012 & 0.128 \\
\hline $22 / 03 / 2010$ & 03:00 & 0 & 5.3 & 17 & 100 & 17 & 0 & 0.000 & 0.000 & 0.128 \\
\hline $22 / 03 / 2010$ & 04:00 & 0 & 3.6 & 18 & 94 & 17 & -1 & 0.018 & 0.018 & 0.146 \\
\hline $22 / 03 / 2010$ & 05:00 & 0 & 3.1 & 17 & 100 & 17 & 0 & 0.023 & 0.023 & 0.170 \\
\hline $22 / 03 / 2010$ & 06:00 & 1 & 3.6 & 17 & 94 & 16 & -1 & 0.015 & 0.015 & 0.185 \\
\hline $22 / 03 / 2010$ & 07:00 & 1 & 4.7 & 18 & 88 & 16 & -2 & -0.010 & 0.000 & 0.185 \\
\hline $22 / 03 / 2010$ & 08:00 & 1 & 6.7 & 21 & 83 & 18 & -3 & -0.015 & 0.000 & 0.185 \\
\hline $22 / 03 / 2010$ & 09:00 & 1 & 7.8 & 24 & 69 & 18 & -6 & -0.030 & 0.000 & 0.185 \\
\hline $22 / 03 / 2010$ & $10: 00$ & 1 & 9.2 & 25 & 61 & 17 & -8 & -0.040 & 0.000 & 0.185 \\
\hline $22 / 03 / 2010$ & $11: 00$ & 1 & 9.2 & 26 & 57 & 17 & -9 & -0.045 & 0.000 & 0.185 \\
\hline $22 / 03 / 2010$ & $12: 00$ & 1 & 10.8 & 25 & 65 & 18 & -7 & -0.035 & 0.000 & 0.185 \\
\hline
\end{tabular}

\section{Appendix 2 - Kriging method}

Kriging is a stochastic spatial interpolation method that predicts the value of a natural phenomenon at non-sampled sites by an unbiased, minimal variance linear combination of observations of the phenomenon at nearby sites. The Kriging tool assumes that the distance or direction between the sample points reflects a spatial correlation that can explain the surface variations. The Kriging tool applies a mathematical function to all points, or certain determined points, located within a specific radius. It determines the output value of each location.

The Kriging tool is particularly suitable for cases where it is known that there is a spatial correlation of distance or a directional deviation in the data. Kriging deduces, by weighting existing readings, the probable values of unmeasured locations. To calculate the interpolated data $\hat{Z}\left(s_{0}\right)$ at a specific location $s_{0}$, the general formula of ordinary Kriging (OK) method consists of a weighted sum of the data (Goovaerts, 1997):

$\hat{Z}\left(s_{0}\right)=\sum_{i=1}^{P} \lambda_{i} Z\left(s_{i}\right)$

Here $Z\left(s_{i}\right)$ corresponds to the measured value at the $i^{\text {th }}$ location, $\lambda_{i}$ the ponderation coefficient to determine and relate to the $i^{\text {th }}$ location, $s_{0}$ the predicted location and $p$ the number of measured data.

With the Kriging method, the $\lambda_{i}$ weighted coefficients are not only based on the distance between the surveyed points and the forecast location, but also on the general spatial organization of the surveyed points. To use the spatial arrangement in the weighing, the spatial autocorrelation is quantified. Thus, in ordinary Kriging, the weighting $\lambda_{i}$ depends on the distance from the forecast location and the spatial relationships between the values recorded around it.

The experimental semi-variogram can be estimated from point pairs:

$\hat{\gamma}(h)=\frac{1}{2 n(h)} \sum_{i=1}^{n(h)}\left[Z\left(s_{i}\right)-Z\left(s_{i}+h\right)\right]^{2}$

where $n(h)=\operatorname{Card}\left\{\left(s_{i}, s_{j}\right) /\left|s_{i}-s_{j}\right| \approx h\right\}$

with "card" represents the number of elements for the given condition.

Classically, estimated semi-variogram are fitted by a spherical variogram model as proposed in previous studies on rainfall spatial estimation (Bargaoui and Chebbi, 2009; Lepioufle et al., 2012; Rahmawati, 2020; Van de Beek et al., 2012). 


\section{Supplementary Materials}

We present below supplementary materials for additional calculated data.

Figure SM1 reports the evolution of the dew summed values $\operatorname{sum}\left(h_{d}\right)$ (dew, mm, full blue line) and the rain summed values $\operatorname{sum}\left(h_{r}\right)$ (rain, mm, interrupted red line) for the studied sites.

Figure SM2 is concerned with the evolution of the mean time $\theta_{0}$ (day) and the maximum time $\theta_{M}$ (day) between (a) rain (orange line), dew (blue short interrupted line) and rain plus dew events (green long interrupted line).

Table SM2 gives the correlation between the sky conditions and the cloud cover in oktas according to NOAA.

Table SM3 reports the yearly $\left(H_{d}\right)$ and monthly $\left(h_{d}\right)$ mean, minimum and maximum dew yields calculated from meteorological data.
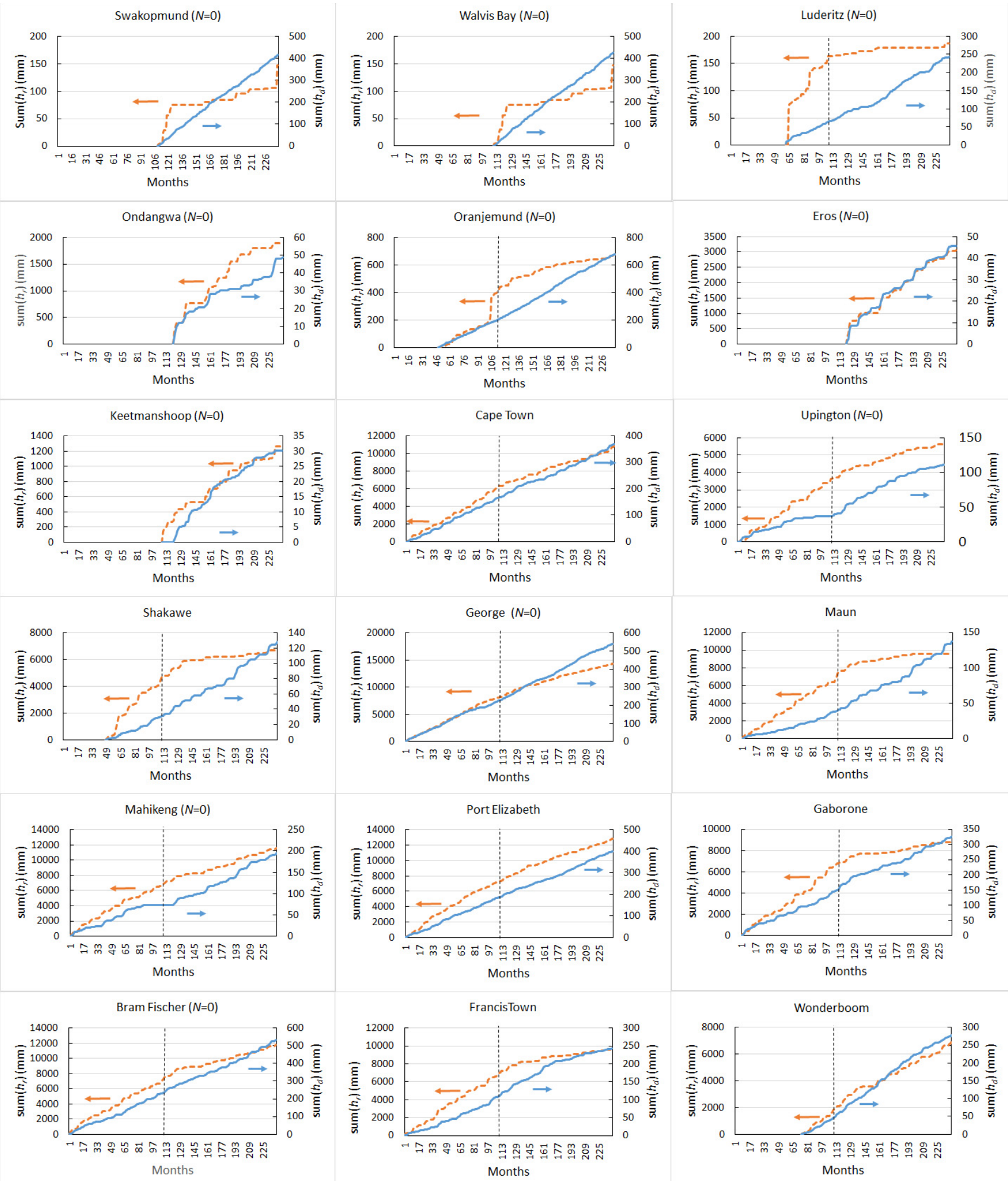

Fig. SM1. Evolution of the summed values $\operatorname{sum}\left(h_{d}\right)\left(\mathrm{dew}, \mathrm{mm}\right.$, full blue line) and sum $\left(h_{r}\right)$ (rain, mm, interrupted red line) for the studied sites. The vertical interrupted line corresponds to a significant decrease of rainfall after 2010 with dew yield remaining constant or weakly increasing. 

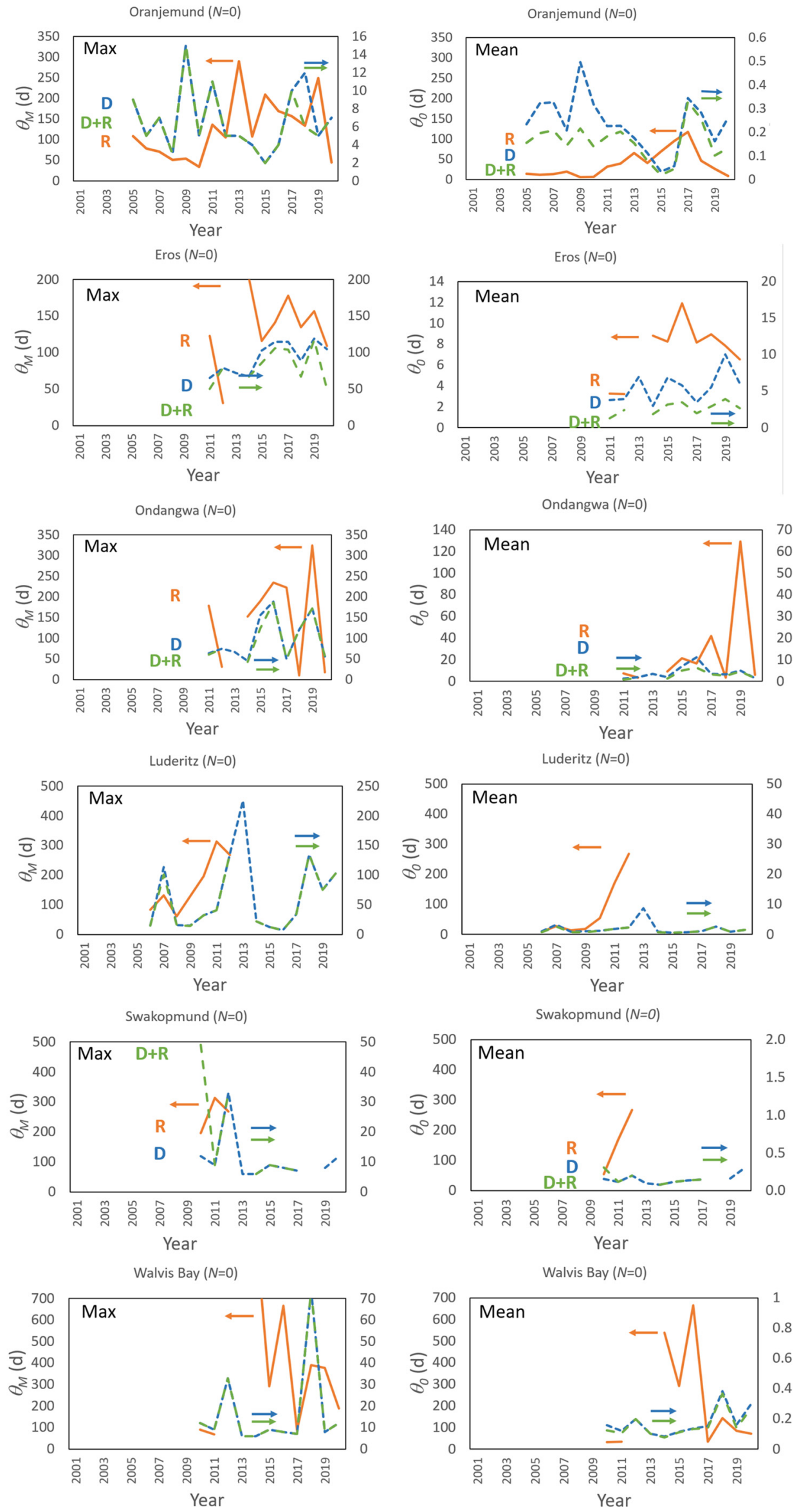

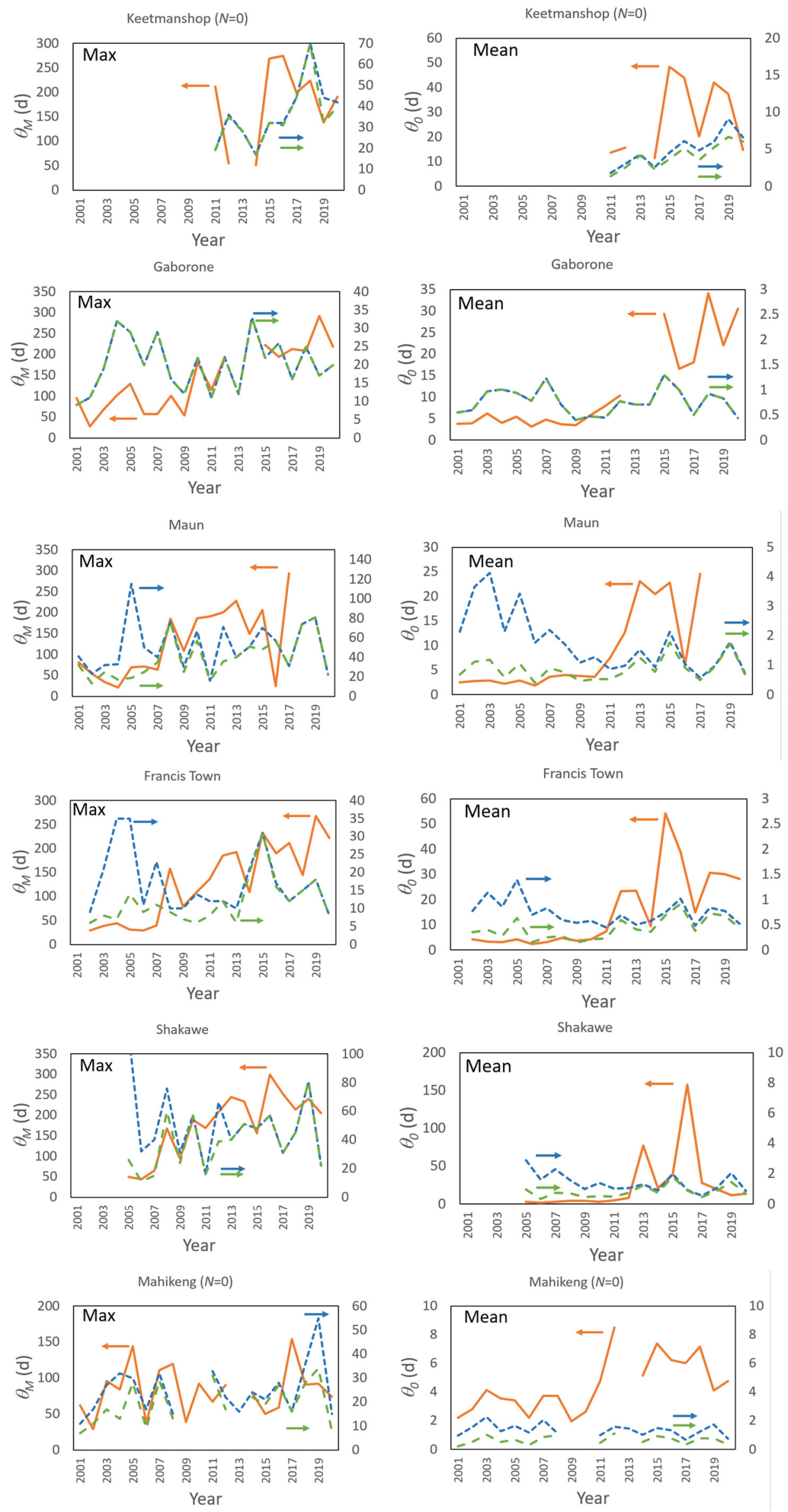

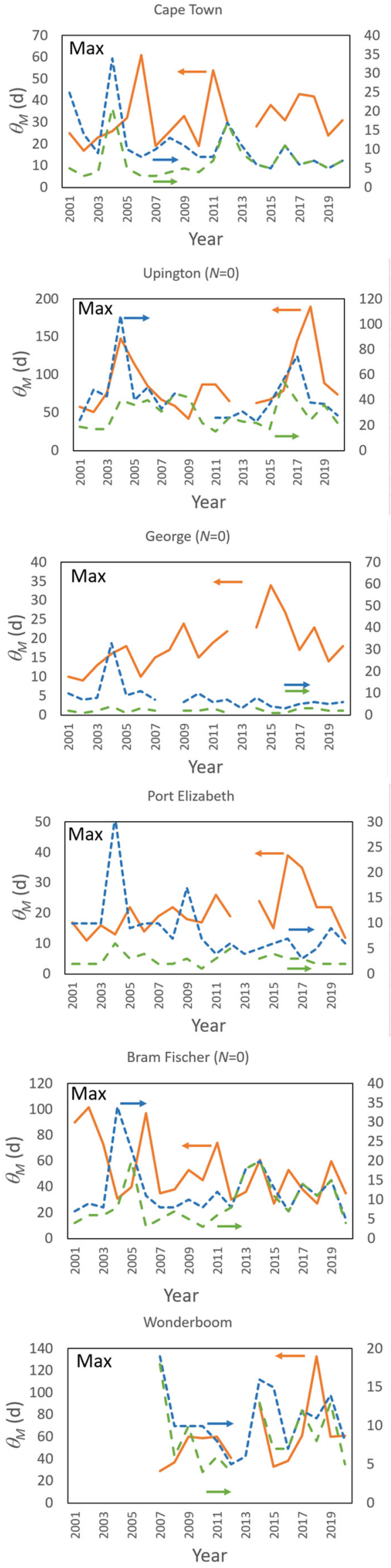
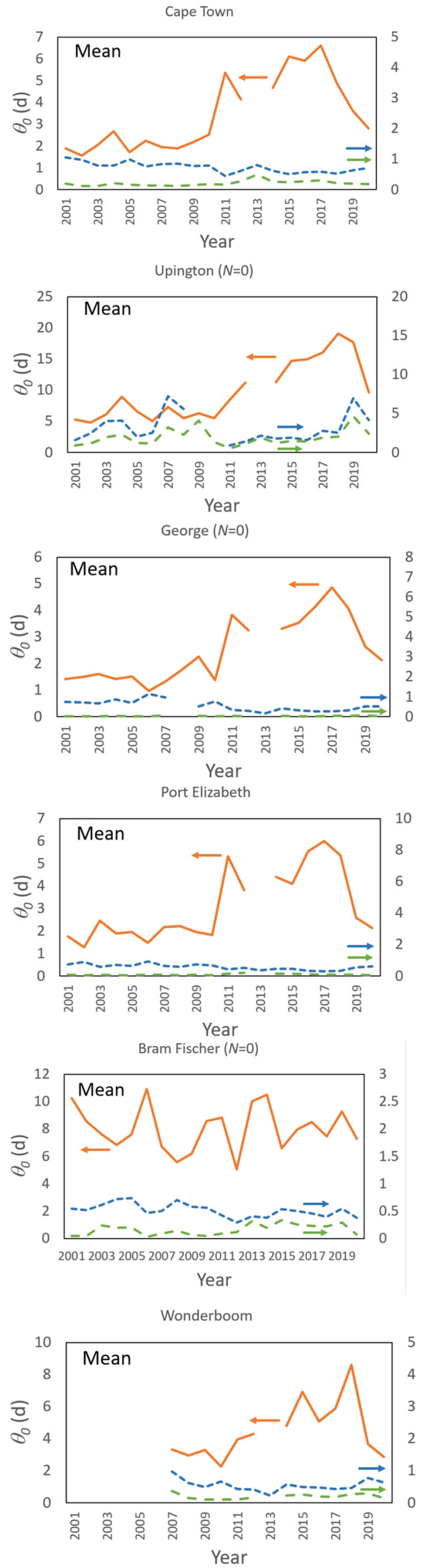

Fig. SM2. Evolution of mean time $\theta_{0}$ (day) and maximum time $\theta_{M}$ (day) between (a) rain (orange line), dew (blue short interrupted line) and rain plus dew events (green long interrupted line). Some curves are interrupted because data are missing. 
Table SM2. Correlation between sky conditions and cloud cover according to NOAA's national weather service glossary, 2021. The abbreviations for sky conditions are the following: $\mathrm{CLR}=$ Clear; FEW $=$ few; $\mathrm{SCT}=$ Scattered; $\mathrm{BKN}=\mathrm{Broken}$; OVC $=$ Overcast.

\begin{tabular}{|c|c|}
\hline Observation & $N$ (oktas) \\
\hline CLR & 0 \\
\hline FEW & 1 \\
\hline SCT & 3 \\
\hline BKN & 5 \\
\hline OVC & 8 \\
\hline
\end{tabular}

Table SM3. Yearly $\left(H_{d}\right)$ and monthly $\left(h_{d}\right)$ mean, minimum and maximum dew yields calculated from meteorological data. The mean evolution data during from 2001 to 2020 are fitted to Eq. (5) with free parameters $\alpha_{d}=d h_{d} / d t$ and $h_{d, 0}$. Red values correspond to a decrease of dew yield evolution, blue values to an increase. Cloud coverage $N$ is assumed to be 0,1 or 3 oktas when cloud cover data are missing (see text and Table 1).

\begin{tabular}{|c|c|c|c|c|c|c|c|c|c|c|}
\hline \multirow{2}{*}{ Site } & \multirow{2}{*}{$\begin{array}{c}N \\
\text { (oktas) }\end{array}$} & \multicolumn{3}{|c|}{$H_{d}(\mathrm{~mm})$} & \multicolumn{3}{|c|}{$h_{d}(\mathrm{~mm})$} & \multirow{2}{*}{$\begin{array}{c}\alpha_{d} \\
\left(\mathrm{~mm} \mathrm{month}^{-1}\right)\end{array}$} & \multirow{2}{*}{$\begin{array}{c}h_{d, 0} \\
(\mathrm{~mm})\end{array}$} & \multirow{2}{*}{$\begin{array}{c}\text { year } \\
\text { frequency } \\
(\%)\end{array}$} \\
\hline & & Mean & Min & Max & Mean & Min & Max & & & \\
\hline \multirow{3}{*}{ Swakopmund } & 0 & 37.7 & 31.2 & 45.5 & 3.1 & 0.0 & 6.8 & -0.002 & 3.2 & 85.6 \\
\hline & 1 & 28.4 & 22.9 & 34.6 & 2.4 & 0.0 & 5.4 & -0.001 & 2.4 & 84.9 \\
\hline & 3 & 12.6 & 9.4 & 15.9 & 1.0 & 0.0 & 2.8 & -0.001 & 1.1 & 79.1 \\
\hline \multirow{3}{*}{ Walvis Bay } & 0 & 38.2 & 31.7 & 46.1 & 3.2 & 0.0 & 6.9 & -0.002 & 3.2 & 85.8 \\
\hline & 1 & 28.8 & 23.3 & 35.1 & 2.4 & 0.0 & 5.4 & -0.001 & 2.4 & 85.0 \\
\hline & 3 & 12.8 & 9.6 & 16.1 & 1.0 & 0.0 & 2.9 & -0.001 & 1.1 & 79.3 \\
\hline \multirow{3}{*}{ Luderitz } & 0 & 16.2 & 3.6 & 26.3 & 1.3 & 0.0 & 4.9 & 0.001 & 1.3 & 42.3 \\
\hline & 1 & 12.6 & 2.8 & 21.4 & 1.0 & 0.0 & 4.3 & 0.001 & 0.1 & 40.3 \\
\hline & 3 & 6.6 & 1.3 & 13.3 & 0.6 & 0.0 & 3.0 & 0.000 & 0.5 & 34.8 \\
\hline \multirow{3}{*}{ Ondangwa } & 0 & 4.9 & 0.4 & 13.5 & 0.4 & 0.0 & 3.7 & -0.004 & 0.6 & 25.3 \\
\hline & 1 & 3.5 & 0.3 & 9.8 & 0.3 & 0.0 & 2.8 & -0.003 & 0.5 & 22.0 \\
\hline & 3 & 1.4 & 0.1 & 3.8 & 0.1 & 0.0 & 1.2 & -0.001 & 0.2 & 13.5 \\
\hline \multirow{3}{*}{ Oranjemund } & 0 & 42.5 & 32.4 & 56.8 & 3.5 & 0.9 & 8.2 & 0.003 & 3.2 & 81.5 \\
\hline & 1 & 32.8 & 23.9 & 45.2 & 2.7 & 0.5 & 6.8 & 0.003 & 2.4 & 80.4 \\
\hline & 3 & 15.4 & 9.6 & 24.3 & 1.3 & 0.2 & 4.1 & 0.003 & 1.0 & 70.6 \\
\hline \multirow{3}{*}{ Eros } & 0 & 4.6 & 1.4 & 8.9 & 0.4 & 0.0 & 2.6 & -0.004 & 0.6 & 16.7 \\
\hline & 1 & 3.5 & 0.9 & 7.0 & 0.3 & 0.0 & 2.1 & -0.003 & 0.5 & 14.6 \\
\hline & 3 & 1.9 & 0.3 & 3.8 & 0.2 & 0.0 & 1.1 & -0.002 & 0.3 & 13.3 \\
\hline \multirow{3}{*}{ Keetmanshoop } & 0 & 3.0 & 0.8 & 5.7 & 0.3 & 0.0 & 1.8 & -0.003 & 0.5 & 18.4 \\
\hline & 1 & 2.2 & 0.5 & 4.2 & 0.2 & 0.0 & 1.4 & -0.002 & 0.3 & 15.3 \\
\hline & 3 & 0.9 & 0.2 & 2.0 & 0.1 & 0.0 & 0.8 & -0.001 & 0.1 & 8.7 \\
\hline Cape Town & - & 18.3 & 8.9 & 24.1 & 1.5 & 0.0 & 5.1 & 0.000 & 1.6 & 58.2 \\
\hline \multirow{3}{*}{ Upington } & 0 & 5.5 & 0.4 & 13.8 & 0.5 & 0.0 & 2.9 & 0.000 & 0.5 & 27.0 \\
\hline & 1 & 5.1 & 0.4 & 13.2 & 0.4 & 0.0 & 2.8 & 0.000 & 0.4 & 26.6 \\
\hline & 3 & 4.5 & 0.4 & 12.4 & 0.4 & 0.0 & 2.6 & 0.001 & 0.3 & 25.7 \\
\hline Shakawe & - & 8.0 & 3.5 & 16.5 & 0.7 & 0.0 & 4.5 & 0.003 & 0.4 & 43.9 \\
\hline \multirow{3}{*}{ George } & 0 & 27.0 & 12.8 & 38.5 & 2.2 & 0.0 & 4.7 & 0.004 & 2.1 & 64.5 \\
\hline & 1 & 25.7 & 12.8 & 37.4 & 2.1 & 0.0 & 4.7 & 0.003 & 1.9 & 64.3 \\
\hline & 3 & 23.3 & 12.8 & 35.3 & 1.9 & 0.0 & 4.7 & 0.002 & 1.6 & 64.0 \\
\hline Maun & - & 6.9 & 1.8 & 18.0 & 0.6 & 0.0 & 4.9 & 0.003 & 0.3 & 40.3 \\
\hline \multirow{3}{*}{ Mahikeng } & 0 & 9.8 & 0.1 & 21.7 & 0.8 & 0.0 & 4.7 & 0.003 & 0.6 & 37.6 \\
\hline & 1 & 8.1 & 0.1 & 18.1 & 0.7 & 0.0 & 4.1 & 0.002 & 0.5 & 35.8 \\
\hline & 3 & 5.5 & 0.1 & 12.2 & 0.5 & 0.0 & 2.9 & 0.001 & 0.3 & 33.2 \\
\hline Port Elizabeth & - & 20.0 & 14.3 & 26.8 & 1.7 & 0.0 & 4.5 & 0.000 & 1.6 & 64.1 \\
\hline Gaborone & - & 16.2 & 6.6 & 26.0 & 1.4 & 0.0 & 5.9 & -0.001 & 1.4 & 57.8 \\
\hline \multirow{3}{*}{ Bram Fischer } & 0 & 26.5 & 14.4 & 38.8 & 2.2 & 0.0 & 7.7 & 0.001 & 2.2 & 66.4 \\
\hline & 1 & 24.0 & 11.9 & 38.7 & 2.0 & 0.0 & 6.8 & 0.000 & 2.2 & 65.6 \\
\hline & 3 & 20.1 & 8.7 & 38.4 & 1.7 & 0.0 & 5.6 & 0.000 & 2.2 & 64.8 \\
\hline Francistown & - & 12.1 & 4.9 & 23.8 & 1.0 & 0.0 & 4.2 & -0.004 & 1.4 & 58.3 \\
\hline Wonderboom & - & 19.9 & 8.0 & 27.4 & 1.7 & 0.0 & 5.0 & 0.000 & 1.7 & 65.5 \\
\hline
\end{tabular}

